\title{
Testing for UIP-Type Relationships: Nonlinearities, Monetary Announcements and Interest Rate Expectations
}

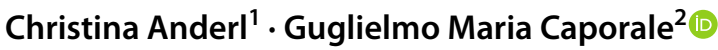

Accepted: 6 October 2021 / Published online: 14 February 2022

(c) The Author(s) 2022

\begin{abstract}
This paper tests for UIP-type relationships by estimating first a benchmark linear Cointegrated VAR including the nominal exchange rate and the interest rate differential as well as central bank announcements, and then a Smooth Transition Cointegrated VAR (STCVAR) model incorporating nonlinearities and also taking into account the role of interest rate expectations. The analysis is conducted for five inflation targeting countries (the UK, Canada, Australia, New Zealand and Sweden) and three non-targeters (the US, the Euro-Area and Switzerland) using daily data from January 2000 to December 2020. While we cannot confirm the validity of UIP in its strictest theoretical sense, we find evidence for the existence of an equilibrium relationship between the exchange rate and the interest rate differential. Specifically, the nonlinear framework appears to be more appropriate to capture the adjustment towards the long-run equilibrium, since the estimated speed of adjustment is substantially faster and the short-run dynamic linkages more significant. Further, interest rate expectations play an important role: a fast adjustment only occurs when the market expects the interest rate to increase in the near future, namely central banks are perceived as more credible when sticking to their goal of keeping inflation at a low and stable rate. Also, central bank announcements have a more sizeable short-run effect in the nonlinear model. Finally, the equilibrium relationship between the exchange rate and the interest rate differential holds better in inflation targeting countries, where monetary authorities appear to achieve a higher degree of credibility.
\end{abstract}

Keywords UIP · Exchange rate $\cdot$ Nonlinearities $\cdot$ Asymmetric adjustment $\cdot$ CVAR (Cointegrated VAR) · STCVAR (Smooth Transition Cointegrated VAR) - Interest rate expectations $\cdot$ Interest rate announcements

JEL Classification C32 $\cdot$ F31 $\cdot$ G15

Guglielmo Maria Caporale

Guglielmo-Maria.Caporale@brunel.ac.uk

1 London South Bank University, London, UK

2 Department of Economics and Finance, Brunel University London, London UB8 3PH, UK 


\section{Introduction}

Uncovered Interest Rate Parity (UIP) is one of the central tenets of international finance; it links interest rate differentials to expected exchange rate changes, and, in particular, it predicts that high yield currencies should depreciate. Various methods have been used to test it empirically; these include simple Ordinary Least Squares (OLS) for estimating the slope coefficient in the UIP relation in early studies (see, for instance, Froot and Thaler 1990; Engel 1996), equilibriumcorrection models of the term structure (Clarida and Taylor 1997) and cointegration tests between UIP and PPP to account for the interaction of goods and capital markets (Johansen and Juselius 1992). Most empirical papers reject the validity of UIP in the short run (see Engel 1996; Sarno, 2005; Banerjee and Singh 2006), and in some cases even in the long run (Lothian 2016). These findings represent a puzzle for which a range of explanations have been offered, such as the existence of a time-varying risk premium (Li et al. 2012; Jiang et al. 2013), the occurrence of rational bubbles (Obstfeld 1987; Canterbery 2000), or deviations from rationality of market participants (Gregory 1987; Chinn and Quayyum 2012).

While there is plenty of evidence on whether or not UIP holds under various monetary policy regimes (Lacerda et al. 2010), in the case of inflation targeting the existing studies only consider emerging markets (Coulibaly and Kempf 2019). The present paper instead examines this issue using daily data for five inflation targeting developed countries, namely the UK, Canada, Australia, New Zealand and Sweden, over the period from January 2000 to December 2020; for comparison purposes, the analysis is also carried out for three economies with alternative monetary regimes, namely the US, the Euro-Area and Switzerland (Neumann and Von Hagen 2002). This classification is based on how central banks identify themselves, despite the fact that they might in fact have adopted different monetary approaches at different points in time. As a first step, a linear Cointegrated Vector Autoregressive (CVAR) benchmark model (Juselius 2018) is estimated which yields a UIP-type relationship between the exchange rate and the interest rate differential; its specification also takes into account the effects of central bank announcements of interest rate changes on the exchange rate and the interest rate differential. However, the more recent literature suggests the possible presence of nonlinearities in the UIP relation; for instance, Smooth Transition Regression models have been found to outperform linear ones in explaining the UIP puzzle (Sarno et al. 2006; Li et al. 2013). Therefore a Smooth Transition Cointegrated Vector Autoregressive (STCVAR) model (Ripatti 2001) is also estimated; the transition variable is interest rate expectations, which is an indicator of central bank credibility often neglected in empirical studies on inflation targeting despite its possible importance; specifically, we use the change in the 30-day interest rate, which is shown to be preferable to alternative transition variables.

The layout of this paper is as follows. Section 2 briefly reviews the relevant literature; Sect. 3 outlines the methodology; Sect. 4 presents the data and discusses the empirical results; Sect. 5 offers some concluding remarks. 


\section{Literature Review}

The validity of UIP has been investigated in numerous papers and from various angles. Estimation methods range from simple linear regressions (Lothian and Wu 2011; Moore and Roche 2010) to more complex multivariate nonlinear models (Sarno et al. 2005). As for cointegration tests, several studies have carried them out to analyse the linkages between spot and forward exchange rates and have provided mixed evidence for the empirical validity of CIP (Covered Interest Rate Parity- e.g., Brenner and Kroner 1995; Zivot, 2000; Clarida et al. 2003); by contrast, there exists only a relatively small set of papers assessing UIP by testing for cointegration between exchange rates and interest rate differentials - again the results have been mixed (Georgoutsos and Kouretas 2002; Weber 2006).

The more recent literature emphasises the importance of taking into account nonlinearities when investigating the UIP relation. For instance, Lyons (2001) estimated a nonlinear model in which deviations of UIP are highly persistent; this finding is explained by the lower Sharpe ratio of the forward rates, which move trade to more lucrative investment opportunities. Sarno et al. (2005) suggested that the forward bias commonly observed in the empirical literature might be a less suitable explanation of forward market inefficiencies than previously assumed. They applied a Smooth Transition Regression (STR) model and found evidence of significant nonlinearities in the UIP relation; in particular, asymmetric deviations from UIP are found to be small, but more persistent, the closer they are to the UIP equilibrium. Baillie and Kilic (2006) analysed nonlinearities in the context of a Logistic Smooth Transition Regression (LSTR) of the spot exchange rate and the lagged forward premium model with different transition variables; their results imply a nonlinear relation, with forward premium being the transition variable. Sarno et al. (2006) estimated a Smooth Transition Regression model for UIP with the expected excess return as the transition variable and also found that deviations from UIP exhibit significant nonlinearities. Using a LSTR model with the risk-adjusted forward premium as the transition variable, Amri (2008) found evidence of nonlinearities in the relation between expected exchange rate changes and the lagged forward premium. Applying the same methodology, but with different transition variables related to currency trading strategies, Baillie and Chang (2011) showed that UIP holds only when carry trade strategies are perceived as profitable - when they are not, their results confirm those of Lyons (2001) and provide additional support for nonlinearities in the UIP relation. Li et al. (2013) followed a similar approach and found empirical support for UIP when using exchange rate volatility and the Sharpe ratio as transition variables, but not when using instead the interest rate differential.

Another issue investigated more recently in the context of UIP is the role of interest rate expectations, which had been found previously to affect the slope of the yield curve (Cook and Hahn 1990), financial ratios (Chen and Ainina 1994) and the exchange rate (Mauleón 1998). Juselius and Stillwagon (2018) reported that interest rate forecasts are the primary source of deviations from the exchange rate and interest rate equilibrium and found an important role for speculative bubbles. Several studies provide evidence that central bank announcements strongly influence interest rate expectations (Moniz 
and De Jong 2014), and that some central banks even use the content of their announcements intentionally to influence interest rate expectations (Tietz 2019). Announcements containing policy rate decisions have been found to have a particularly strong effect on asset prices, including the exchange rate and interest rate, compared to other types of announcements (Sager and Taylor 2004; Rosa and Verga 2018).

\section{Empirical Methodology}

To investigate the issues of interest, as a first step we estimate a linear Cointegrated VAR as in Juselius (2018) for the UIP relation. In order for two variables to cointegrate and be linked by a long-run equilibrium relationship, they must exhibit the same non-zero order of integration. Therefore, to establish if this condition is satisfied, prior to this estimation we perform unit root tests for the individual series, specifically the Dickey Fuller Generalised Least Squares (DF-GLS) and the KwiatkowskiPhillips-Schmidt-Shin (KPSS) tests. We the employ the Johansen (1991) cointegration trace and eigenvalue tests to test for cointegration between the series.

\subsection{The Cointegrated VAR (CVAR) Model}

The standard linear Cointegrated VAR model takes the following general form:

$$
\Delta x_{t}=\Pi x_{t-1}+\sum_{i=1}^{q} \gamma \Delta x_{t-i}+\Phi D_{t}+\varepsilon_{t}
$$

where $x_{t}$ is a vector with the series under examination, $\Delta$ is the difference operator, $\Pi=\theta \beta^{\prime}$ is a matrix given by the product of two vectors including the adjustment and the cointegrating coefficients respectively, $\Gamma_{i}$ is the coefficient matrix of the parameters governing the short-run behaviour of the variables, $D_{t}$ is a vector of exogenous dummy variables and $\Phi$ the corresponding coefficient matrix. The model has $r$ cointegrating relations and $p$ endogenous variables; if cointegration holds, whenever the endogenous variables are pushed away from the long-run equilibrium by exogenous shocks, they gradually revert to it, the size of the coefficient $\theta$ representing the adjustment speed. Our empirical CVAR model is specified as follows:

$$
\begin{gathered}
\Delta s_{t}=\theta \beta^{\prime} x_{t-1}+\sum_{i=1}^{q} \gamma_{11, i} \Delta s_{t-i}+\sum_{i=1}^{q} \gamma_{12, i} \Delta \tilde{i}_{t-i}+\varphi_{1} d_{p}+\varphi_{2} d_{n}+\varepsilon_{t} \\
\Delta \tilde{i}_{t}=\theta \beta^{\prime} x_{t-1}+\sum_{i=1}^{q} \gamma_{21, i} \Delta s_{t-i}+\sum_{i=1}^{q} \gamma_{22, i} \Delta \tilde{i}_{t-i}+\varphi_{1} d_{p}+\varphi_{2} d_{n}+\varepsilon_{t}
\end{gathered}
$$

where $s_{t}$ is the nominal exchange rate, $\tilde{i}_{t}=i_{t}-i_{t}^{*}$ is the difference between the domestic and foreign interest rates, and $d_{p}$ and $d_{n}$ are two dummies corresponding respectively to the announcement dates for interest rate increases and decreases - they are set equal to 1 on the announcement date and 0 elsewhere and only enter the short-run deterministic component of the model, thus capturing the transitory 
impulse effects of policy changes without affecting the long-run UIP mechanism (Juselius 2018). All other variables are defined as before. The lag length is chosen using appropriate lag selection criteria, such as the Likelihood-Ratio (LR) Test, to select the most parsimonious specification which ensures that there is no serial correlation.

When estimating a CVAR model, there are two important issues to consider to specify it correctly. One is whether or not deterministic trends should be included in the short-run dynamics and/or the long-run equilibrium relations. In our case they are not required, since the exchange rate and interest rates tend to have a zero mean growth rate and any trending behaviour should be stochastic. However, Juselius (2017) suggests to test for the order of integration of the variables within the system. For this purpose we employ a test of the hypothesis that the individual variables are at most I(1) versus being closer to $\mathrm{I}(2)$ after the model has been specified. The other issue is that model identification is only possible when appropriate restrictions are placed on the model parameters. Long-run restrictions have to satisfy the identification rank conditions for the model (Juselius 2018). In order for economic identification of the short-run structure to be possible, the residuals need to be uncorrelated. Therefore, we perform the Breusch-Godfrey Lagrange Multiplier (LM) test for residual serial correlation. In addition, we test the CVAR models for their stability.

\subsection{The Smooth Transition Cointegrated VAR Model}

Linear models might be unsuitable for the UIP relation as the error correction coefficient might change in a nonlinear fashion. Therefore, a nonlinear Smooth Transition Cointegrated Vector Autoregressive (STCVAR) model (Ripatti 2001), which allows for asymmetric dynamic adjustment to the UIP equilibrium relationship, might be more appropriate. The general model takes the following form:

$$
\Delta x_{t}=\theta \beta^{\prime} x_{t-1} \cdot G\left(z_{t}\right)+\left(\sum_{i=1}^{q} \Gamma_{i} \Delta x_{t-i}\right) \cdot G\left(z_{t}\right)+\Phi D_{t} \cdot G\left(z_{t}\right)+\varepsilon_{t}
$$

where $x_{t}$ is the $(p \times 1)$ vector of the series of interest, $\Delta$ is again the difference operator, $\Gamma_{i}$ is the $(p \times p)$ matrix of the short-run coefficients, $D_{t}$ is a vector of dummy variables with a parameter matrix $\Phi$, and as before the $\theta$ and $\beta$ vectors include the adjustment speed and cointegrating coefficients respectively. $G\left(z_{t}\right)=\operatorname{diag}\left\{G_{1}\left(\gamma_{1}, c_{1}, z_{t}\right), \ldots, G_{m}\left(\gamma_{m}, c_{m}, z_{t}\right)\right\}$ is the transition function, where $\gamma$ is the slope parameter, $c$ is the transition value and $z_{t}$ is the transition variable. The transition function allows the parameters of the model to change smoothly from one regime to the next as a function of the transition variable $z_{t}$.

The transition variable in our empirical specification is the change in the 30-day interest rate, which can be seen as an indicator of changes in interest rate expectations. Central bank meetings and decisions about changes in the interest rate generally occur in monthly cycles. Therefore the 30-day interest rate should not vary greatly over the span of a month if interest rate expectations are aligned with the official monetary policy rate (Connolly and Kohler 2004). If instead it does, this implies a change in market expectations of the monetary policy rate in the near 
future and can indicate that the central bank is not perceived as fully credible. The empirical model corresponding to Eq. (3) can be written as follows:

$$
\begin{aligned}
& \Delta s_{t}=\theta \beta^{\prime} x_{t-1} \cdot G\left(z_{t}\right)+\left(\sum_{i=1}^{q} \gamma_{11, i} \Delta s_{t-i}+\sum_{i=1}^{q} \gamma_{12, i} \Delta \tilde{i}_{t-i}\right) \cdot G\left(z_{t}\right)+\left(\varphi_{1} d_{p}+\varphi_{2} d_{n}\right) \cdot G\left(z_{t}\right)+\varepsilon_{t} \\
& \Delta \tilde{i}_{t}=\theta \beta^{\prime} x_{t-1} \cdot G\left(z_{t}\right)+\left(\sum_{i=1}^{q} \gamma_{21, i} \Delta s_{t-i}+\sum_{i=1}^{q} \gamma_{22, i} \Delta \tilde{i}_{t-i}\right) \cdot G\left(z_{t}\right)+\left(\varphi_{1} d_{p}+\varphi_{2} d_{n}\right) \cdot G\left(z_{t}\right)+\varepsilon_{t}
\end{aligned}
$$

where all variables are defined as before. The lag length is chosen using the Likelihood-Ratio (LR) Test to select the most parsimonious specification which ensures that there is no serial correlation.

\subsection{Testing for Smooth Transition Nonlinearity}

An important step prior to the estimation of the nonlinear model is performing nonlinearity tests. A suitable one in our case is a test for linearity against a STAR-type model. The null is that $\gamma=0$ versus $\gamma>0$, where $\gamma$ is the slope parameter, which indicates the smoothness of the transition from one regime to another. Teräsvirta and Yang (2014) report that Rao's F statistic has better finite sample properties than other tests. The test statistic for the hypothesis $H_{0}: \theta=\theta_{0}$ is $R S S=S\left(\theta_{0}\right)^{\prime}\left[I\left(\theta_{0}\right)\right]^{-1} S\left(\theta_{0}\right)$, where $S$ is the score vector and $I$ is the Fisher information matrix. This test follows a chi-square distribution with $r$ degrees of freedom, where $r$ is the number of parameter vectors (Rao 1948). If linearity is rejected against a smooth transition nonlinearity type, one then also tests for the type of transition function. This is done by choosing a transition variable and then performing a test of the shape of the transition function. The test is based on a conventional STAR model, which can be expressed as follows:

$$
y_{t}=\pi^{\prime} X_{t}+F\left(z_{t-d}, \gamma, c\right)+\Theta^{\prime} X_{t}+u_{t}
$$

where $X_{t}=\left(1, y_{t-1}, \ldots, y_{t-p}\right)$ and $F\left(z_{t-d}, \gamma, c\right)$ is the transition function, $z_{t-d}$ is the transition variable with lag $d, \gamma$ is the smoothness parameter and $c$ is the transition value. STAR-type models can either be logistic or exponential. The first order logistic transition function is:

$$
F\left(z_{t-d}, \gamma, c\right)=\left[1-\exp \left\{-\gamma\left(z_{t-d}-c\right)^{2}\right\}\right]
$$

and the exponential transition function is:

$$
F\left(z_{t-d}, \gamma, c\right)=\left[\left\{1+\exp \left(-\gamma\left(z_{t-d}-c\right)\right)\right\}^{-1}-\frac{1}{2}\right]
$$

After the null of linearity is rejected one has to choose between a logistic and exponential transition function. For this purpose, Escribano and Jordá (2001) 
suggest a selection process based on the below auxiliary regression, which is a 4 th order Taylor approximation of the generic transition function $F\left(z_{t-d}, \gamma, c\right)$ :

$$
y_{t}=\delta_{0}+\delta_{1}^{\prime} \tilde{x}_{t}+\beta_{1}^{\prime} \tilde{x}_{t} z_{t-d}+\beta_{2}^{\prime} \tilde{x}_{t} z_{t-d}^{2}+\beta_{3}^{\prime} \tilde{x}_{t} z_{t-d}^{3}+\beta_{4}^{\prime} \tilde{x}_{t} z_{t-d}^{4}+\vartheta_{3 t}
$$

Using an F-test, the following hypotheses are tested:

$$
\begin{gathered}
H_{0_{3}}: \beta_{3}^{\prime}=0 \\
H_{0_{2}}: \beta_{2}^{\prime}=0 \mid \beta_{3}^{\prime}=0 \\
H_{0_{1}}: \beta_{1}^{\prime}=0 \mid \beta_{2}^{\prime}=\beta_{3}^{\prime}=0
\end{gathered}
$$

Escribano and Jordá (2001) suggest the use of an F-test to test the null hypothesis $H_{0_{L}}: \beta_{2}^{\prime}=\beta_{4}^{\prime}=0$ and to obtain the p-value for the test statistic $F_{L}$, and also to test the null hypothesis $H_{0_{L}}: \beta_{1}^{\prime}=\beta_{3}^{\prime}=0$ and obtain the p-value for the test statistic $F_{E}$. If the p-value of $F_{E}$ is the minimum p-value, a logistic model should be selected; otherwise, the exponential model is more appropriate. We follow the method proposed by Escribano and Jordá (2001 - EJ henceforth) to select the most suitable transition function for each model.

\subsection{Misspecification Tests for Smooth Transition Models}

Nonlinear smooth transition models can suffer from several types of misspecification. Eitrheim and Teräsvirta (1996) develop parametric testing procedures with desirable power properties to address these issues in smooth transition models. The first is a test of no additional nonlinearity, which is an LM-type test of the null of remaining nonlinearity against the alternative of no remaining nonlinearity. The second is a parameter constancy test, which is also an LM-type test. The third is an LM test of the serial independence of the error (Lukkonen and Teräsvirta 1988). In order to confirm the suitability of our choice of transition variable we also estimate STCVAR models which include alternative transitions variables, more precisely, the relative 30-day interest rate, the absolute change in the 30-day interest rate, the 30-day interest rate minus the overnight rate and the 10-year interest rate minus the overnight rate. To investigate in greater depth the role of central bank announcements, we also estimate a STCVAR model which excludes the announcement dummy variables.

\section{Data and Empirical Results}

\subsection{Data Description}

We use daily data from 1st January 2000 to 31st December 2020 for five inflation targeting countries (the UK, Canada, Australia, New Zealand and Sweden) and also 
for three non-inflation targeting economies (the US, the Euro-Area and Switzerland; Neumann and Von Hagen 2002). The nominal exchange rate series are obtained from the Pacific Exchange Rate Service database. The interest rate series and their sources are the following: for the UK the series used is the Bank of England Overnight London Interbank Offered Rate (LIBOR) based on the British Pound which is obtained from the Federal Reserve Bank of St Louis economic database; for Canada the series is the Bank of Canada Overnight Repo Rate taken from the Bank of Canada statistics database; for Australia it is the Reserve Bank of Australia Interbank Overnight Cash Rate retrieved from the Reserve Bank of Australia statistics database; for New Zealand it is the Reserve Bank of New Zealand Interbank Overnight Cash Rate reported in the Reserve Bank of New Zealand statistics database; for Sweden it is the Swedish Riksbank Deposit Rate from the Riksbank statistics database; for the US it is the Treasury Overnight London Interbank Offered Rate (LIBOR) based on the US Dollar, for Switzerland the Swiss National Bank Overnight London Interbank Offered Rate (LIBOR) based on the Swiss Franc, both series coming from the Federal Reserve Bank of St Louis economics database; finally, for the EuroArea we use the European Central Bank EMU Convergence criteria daily interest rate series obtained from Eurostat. Central bank announcement dates are collected from the Bloomberg release calendars for individual central banks and include announcements of both positive and negative interest rate changes. The data for all 30-day interest rate series are obtained from Bloomberg. For the UK, the series is the 1-month LIBOR rate for the British pound; for Canada, the series is the 1-month Canadian banker acceptance rate; for Australia and New Zealand, the series are the 30-day interbank cash rate future contract; for Sweden, it is the 1-month interbank offered rate; for the US the 30-day Federal funds future rate; for the Euro-Area the 1-month EURIBOR rate; finally, for Switzerland the 1-month LIBOR for the Swiss franc. Daily changes are included in the model as a measure of changes in the expected interest rate over the following month. Data for the 10-year interest rates for all countries are also obtained from Bloomberg; specifically they are the daily rates on government bonds with 10-year maturity.

Exchange rates and interest rate differentials are defined in a consistent way, namely the domestic currency appears in the numerator and the foreign one in the denominator in the case of the former variable, whilst the latter variable is calculated as domestic minus foreign interest rates. For instance, CADAUD denotes the exchange rate constructed as domestic currency (in this case the Canadian dollar) units per unit of foreign currency (in this case the Australian dollar) and the interest differential is calculated as domestic interest rate (in this case the Canadian one) relative to the foreign interest rate (in this case the Australian one).

\subsection{Unit Root and Cointegration Tests}

We first perform the DF-GLS and KPSS unit root tests on the nominal exchange rate and the interest rate differential series. The results of these tests are reported in Table 1 and confirm that all series are integrated of order $I(1)$. 
Table 1 Unit Root Test Results

\begin{tabular}{|c|c|c|c|c|}
\hline & \multicolumn{2}{|l|}{ DF-GLS Test } & \multicolumn{2}{|l|}{ KPSS Test } \\
\hline & Level series & Differenced series & Level series & Differenced series \\
\hline \multicolumn{5}{|c|}{ Nominal Exchange Rates } \\
\hline GBPCAD & -1.981 & $-15.484 * * *$ & $89.2 * * *$ & 0.042 \\
\hline GBPAUD & -1.906 & $-16.760 * * *$ & $103 * * *$ & 0.0676 \\
\hline GBPNZD & -2.616 & $-16.538 * * *$ & $68.8 * * *$ & 0.0315 \\
\hline GBPSEK & -2.314 & $-14.824 * * *$ & $94.7 * * *$ & 0.0326 \\
\hline CADAUD & -2.532 & $-13.089 * * *$ & $51.3^{* * *}$ & 0.0292 \\
\hline CADNZD & -2.741 & $-15.218 * * *$ & $32.2 * * *$ & 0.0282 \\
\hline CADSEK & -2.241 & $-15.186 * * *$ & $17.4^{* * *}$ & 0.0181 \\
\hline AUDNZD & -2.524 & $-14.633 * * *$ & $80.7 * * *$ & 0.0382 \\
\hline AUDSEK & -2.789 & $-13.267 * * *$ & $59.2 * * *$ & 0.0203 \\
\hline NZDSEK & -2.033 & $-15.562 * * *$ & $19 * * *$ & 0.0133 \\
\hline USDEUR & -1.553 & $-14.132 * * *$ & $149 * * *$ & 0.0675 \\
\hline USDCHF & -2.005 & $-15.993 * * *$ & $140 * * *$ & 0.029 \\
\hline EURCHF & -1.598 & $-16.754 * * *$ & $97.7 * * *$ & 0.0653 \\
\hline \multicolumn{5}{|c|}{ Interest Rate Differentials } \\
\hline UK-Canada & -2.038 & $-17.027 * * *$ & $40.5^{* * *}$ & 0.0061 \\
\hline UK-Australia & -0.056 & $-16.351 * * *$ & $133 * * *$ & 0.0105 \\
\hline UK-New Zealand & -0.443 & $-17.102 * * *$ & $123 * * *$ & 0.0031 \\
\hline UK-Sweden & -1.007 & $-15.722 * * *$ & $61.7 * * *$ & 0.0587 \\
\hline Canada-Australia & -0.357 & $-16.056^{* * *}$ & $138 * * *$ & 0.0407 \\
\hline Canada-New Zealand & -0.463 & $-17.295 * * *$ & $108 * * *$ & 0.0084 \\
\hline Canada-Sweden & -0.921 & $-16.653 * * *$ & $64.5^{* * *}$ & 0.0219 \\
\hline Australia-New Zealand & -1.517 & $-17.606 * * *$ & $74.7 * * *$ & 0.0098 \\
\hline Australia-Sweden & -0.261 & $-16.425 * * *$ & $29.8 * * *$ & 0.0249 \\
\hline New Zealand-Sweden & -0.276 & $-17.566 * * *$ & $35.3 * * *$ & 0.119 \\
\hline US- Euro Area & -0.852 & $-12.248 * * *$ & $119 * * *$ & 0.0782 \\
\hline US-Switzerland & -1.811 & $-17.526 * * *$ & $116^{* * *}$ & 0.0019 \\
\hline Euro Area-Switzerland & -2.231 & $-16.243 * * *$ & $25.3 * * *$ & 0.0012 \\
\hline
\end{tabular}

*** significant at $1 \%$ level

DF-GLS: $H_{0}$ : variable contains a unit root KPSS: $H_{0}$ : variable is trend stationary

$H_{1}$ : variable is stationary $\quad H_{1}$ : variable is not trend stationary

Therefore, we proceed to test for cointegration between the series. The results of the Johansen cointegration trace and eigenvalue tests are reported in Table 2 and show that the cointegration rank is $r=1$, i.e. there exists a single cointegration relation in each case which can be interpreted as the UIP equilibrium.

\subsection{Results for the Linear CVAR Model}

Table 3 reports the results of LR tests to determine the optimal lag length for each CVAR model. 
Table 2 Johansen Trace and Eigenvalue Tests for Cointegration

\begin{tabular}{lllll}
\hline & Trace Test & & Eigenvalue Test \\
\hline & Test 1 & Test 2 & Test 1 & Test 2 \\
UK-Canada & $0.0003 * * *$ & 0.4879 & $0.0001 * * *$ & 0.4879 \\
UK-Australia & $0.0129 * *$ & 0.9323 & $0.0023 * * *$ & 0.9323 \\
UK-New Zealand & $0.0130 * *$ & 0.4064 & $0.0103 * * *$ & 0.4064 \\
UK-Sweden & $0.0022^{* *}$ & 0.2151 & $0.0012 * * *$ & 0.6755 \\
Canada-Australia & $0.0252^{* *}$ & 0.5501 & $0.0149 * * *$ & 0.5501 \\
Canada-New Zealand & $0.0246 * *$ & 0.5144 & $0.0014 * * *$ & 0.5186 \\
Canada-Sweden & $0.0364 * *$ & 0.8298 & $0.0068 * * *$ & 0.2032 \\
Australia-New Zealand & $0.0006 * * *$ & 0.6791 & $0.0001 * * *$ & 0.6791 \\
Australia-Sweden & $0.0005 * * *$ & 0.5822 & $0.0019 * * *$ & 0.1831 \\
New Zealand-Sweden & $0.0185 * *$ & 0.9249 & $0.0037 * * *$ & 0.9249 \\
US-Euro Area & $0.0057 * * *$ & 0.3192 & $0.0005 * * *$ & 0.9924 \\
US-Switzerland & $0.0000^{* * *}$ & 0.5672 & $0.0000 * * *$ & 0.5672 \\
Euro Area-Switzerland & $0.0000^{* * *}$ & 0.6506 & $0.0000 * * *$ & 0.6506 \\
\hline
\end{tabular}

Trace Test:

Eigenvalue Test:

Test $1: H_{0}: r=0 ; H_{1}: r=1 ; 95 \%$ Critical Test $1: H_{0}: r=0 ; H_{1}: r=1 ; 95 \%$ Critical value: value: 25.87

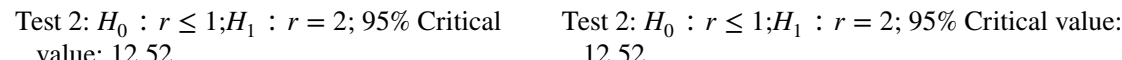
value: 12.52 $r$ denotes the cointegration rank and number of significant vectors. P-vales reported for all

The estimation results for the linear Cointegrated Vector Autoregressive model are reported in Tables 4, 5 and 6. We find that a long-run relationship between the exchange rate and the interest rate differential exists in most cases. Since we have

Table 3 Lag Selection in the CVAR Model

\begin{tabular}{|c|c|c|c|c|c|c|c|}
\hline Lag & GBPCAD & GBPAUD & GBPNZD & GBPSEK & CADAUD & CADNZD & CADSEK \\
\hline 1 & 202.52 & 281.66 & 378.38 & 157.26 & 34.535 & 575.39 & 31.95 \\
\hline 2 & 111.79 & 148.31 & 112.84 & 75.801 & 35.189 & 63.019 & $3.7235 *$ \\
\hline 3 & $84.766^{*}$ & $90.054 *$ & 125.91 & 41.771 & 16.667 & $98.968^{*}$ & 1.0889 \\
\hline 4 & 83.636 & 92.736 & 88.224 & 36.602 & 27.725 & 38.668 & 3.857 \\
\hline 5 & 25.886 & 25.359 & 27.667 & $9.5262 *$ & $1.961 *$ & 16.924 & 0.749 \\
\hline 6 & 44.641 & 59.112 & $58.974 *$ & 34.912 & 8.4577 & 9.7212 & 4.657 \\
\hline Lag & AUDNZD & AUDSEK & NZDSEK & USDEUR & USDCHF & EURCHF & \\
\hline 1 & 569.2 & 19.606 & 268.73 & 5.4953 & 789.68 & 791.48 & \\
\hline 2 & 53.556 & 9.4629 & 11.58 & 28.972 & 243.08 & 212.93 & \\
\hline 3 & $73.951^{*}$ & $4.4599 *$ & 33.226 & $3.1102 *$ & 100.29 & $79.738 *$ & \\
\hline 4 & 64.427 & 16.419 & 16.652 & 14.305 & 263.16 & 278.17 & \\
\hline 5 & 21.852 & 6.5165 & $9.84 *$ & 32.522 & $85.31 *$ & 333.98 & \\
\hline 6 & 13.433 & 11.993 & 0.729 & 21.335 & 335.8 & 81.863 & \\
\hline
\end{tabular}

Likelihood Ratio Test: sequential modified LR test statistic at 5\%

* indicates chosen lag at which there exists no serial correlation 
Table 4 Linear Cointegrated Vector Autoregressive Model Results for Non-Targeting Countries

\begin{tabular}{|c|c|c|c|c|c|c|}
\hline \multirow{3}{*}{$\begin{array}{l}\text { Independent } \\
\text { Variables }\end{array}$} & \multirow{2}{*}{\multicolumn{2}{|c|}{$\frac{\text { USDEUR }}{\text { Dependent Variables }}$}} & \multicolumn{2}{|l|}{ USDCHF } & \multicolumn{2}{|l|}{ EURCHF } \\
\hline & & & & & & \\
\hline & $\Delta s_{t}$ & $\Delta \tilde{i}_{t}$ & $\Delta s_{t}$ & $\Delta \tilde{i}_{t}$ & $\Delta s_{t}$ & $\Delta \tilde{i}_{t}$ \\
\hline$\mu_{0}$ & $\begin{array}{l}0.00002 \\
(0.00006)\end{array}$ & $\begin{array}{l}0.00021 \\
(0.00025)\end{array}$ & $\begin{array}{l}0.00003 \\
(0.00006)\end{array}$ & $\begin{array}{l}0.00039 \\
(0.00181)\end{array}$ & $\begin{array}{l}0.00003 \\
(0.00004)\end{array}$ & $\begin{array}{l}0.00017 \\
(0.0019)\end{array}$ \\
\hline$\Delta s_{t-1}$ & $\begin{array}{l}0.00753 \\
(0.0114)\end{array}$ & $\begin{array}{l}-0.047 \\
(0.05)\end{array}$ & $\begin{array}{l}0.0273 * * \\
(0.0114)\end{array}$ & $\begin{array}{l}0.00697 \\
(0.325)\end{array}$ & $\begin{array}{l}0.127 * * * \\
(0.0114)\end{array}$ & $\begin{array}{l}0.801 \\
(0.551)\end{array}$ \\
\hline$\Delta s_{t-2}$ & $\begin{array}{l}0.00628 \\
(0.0114)\end{array}$ & $\begin{array}{l}0.0351 \\
(0.05)\end{array}$ & $\begin{array}{l}0.00788 \\
(0.0114)\end{array}$ & $\begin{array}{l}-0.159 \\
(0.325)\end{array}$ & $\begin{array}{l}-0.0304 * * * \\
(0.0115)\end{array}$ & $\begin{array}{l}0.118 \\
(0.555)\end{array}$ \\
\hline$\Delta s_{t-3}$ & $\begin{array}{l}-0.00048 \\
(0.0114)\end{array}$ & $\begin{array}{l}0.0286 \\
(0.05)\end{array}$ & $\begin{array}{l}-0.013 \\
(0.0114)\end{array}$ & $\begin{array}{l}0.519 \\
(0.324)\end{array}$ & $\begin{array}{l}-0.0164 \\
(0.0114)\end{array}$ & $\begin{array}{l}0.0502 \\
(0.551)\end{array}$ \\
\hline$\Delta s_{t-4}$ & & & $\begin{array}{l}-0.0275^{* *} \\
(0.0114)\end{array}$ & $\begin{array}{l}0.129 \\
(0.324)\end{array}$ & & \\
\hline$\Delta s_{t-5}$ & & & $\begin{array}{l}0.0067 \\
(0.0114)\end{array}$ & $\begin{array}{l}0.383 \\
(0.324)\end{array}$ & & \\
\hline$\Delta \tilde{i}_{t-1}$ & $\begin{array}{l}-0.00111 \\
(0.0026)\end{array}$ & $\begin{array}{l}-0.0254^{* *} \\
(0.0114)\end{array}$ & $\begin{array}{l}0.00043 \\
(0.00039)\end{array}$ & $\begin{array}{l}-0.444 * * * \\
(0.0112)\end{array}$ & $\begin{array}{l}-0.00004 \\
(0.00024)\end{array}$ & $\begin{array}{l}-0.365 * * * \\
(0.0116)\end{array}$ \\
\hline$\Delta \tilde{i}_{t-2}$ & $\begin{array}{l}-0.00209 \\
(0.0026)\end{array}$ & $\begin{array}{l}-0.0599 * * * \\
(0.0114)\end{array}$ & $\begin{array}{l}-0.00004 \\
(0.00042)\end{array}$ & $\begin{array}{l}-0.295 * * * \\
(0.0119)\end{array}$ & $\begin{array}{l}0.00002 \\
(0.00025)\end{array}$ & $\begin{array}{l}-0.201 * * * \\
(0.012)\end{array}$ \\
\hline$\Delta \tilde{i}_{t-3}$ & $\begin{array}{l}0.00193 \\
(0.0026)\end{array}$ & $\begin{array}{l}-0.0171 \\
(0.0114)\end{array}$ & $\begin{array}{l}-0.00044 \\
(0.00042)\end{array}$ & $\begin{array}{l}-0.234 * * * \\
(0.0121)\end{array}$ & $\begin{array}{l}-0.00010 \\
(0.00024)\end{array}$ & $\begin{array}{l}-0.100 * * * \\
(0.0114)\end{array}$ \\
\hline$\Delta \tilde{i}_{t-4}$ & & & $\begin{array}{l}0.00004 \\
(0.00042)\end{array}$ & $\begin{array}{l}-0.266^{* * *} \\
(0.0119)\end{array}$ & & \\
\hline$\Delta \tilde{i}_{t-5}$ & & & $\begin{array}{l}-0.00017 \\
(0.00039)\end{array}$ & $\begin{array}{l}-0.206^{* * * *} \\
(0.0112)\end{array}$ & & \\
\hline$\theta$ & $\begin{array}{l}-0.00081^{*} \\
(0.00044)\end{array}$ & $\begin{array}{l}0.00008 \\
(0.0019)\end{array}$ & $\begin{array}{l}-0.00056^{*} \\
(0.00033)\end{array}$ & $\begin{array}{l}0.0118 \\
(0.00925)\end{array}$ & $\begin{array}{l}-0.00012 \\
(0.00039)\end{array}$ & $\begin{array}{l}0.170 * * * \\
(0.0186)\end{array}$ \\
\hline$d_{p}$ & $\begin{array}{l}0.00004 \\
(0.0003)\end{array}$ & $\begin{array}{l}-0.0032^{* *} \\
(0.0015)\end{array}$ & $\begin{array}{l}0.00160 * * * \\
(0.000491)\end{array}$ & $\begin{array}{l}-0.00561 \\
(0.014)\end{array}$ & $\begin{array}{l}0.00003 \\
(0.00027)\end{array}$ & $\begin{array}{l}-0.00419 \\
(0.0131)\end{array}$ \\
\hline$d_{n}$ & $\begin{array}{l}0.00026 \\
(0.0009)\end{array}$ & $\begin{array}{l}-0.0156^{* * * *} \\
(0.0039)\end{array}$ & $\begin{array}{l}0.00259 * * * \\
(0.000815)\end{array}$ & $\begin{array}{l}-0.021 \\
(0.0232)\end{array}$ & $\begin{array}{l}0.00259 * * * \\
(0.00049)\end{array}$ & $\begin{array}{l}-0.00942 \\
(0.0236)\end{array}$ \\
\hline
\end{tabular}

* significant at $10 \%$ level, $* *$ significant at $5 \%$ level, $* * *$ significant at $1 \%$ level. Standard errors in parentheses

previously established that the exchange rate series are integrated of order I(1), they enter the cointegration relationship in the CVAR model in their levels, not their first differences as specified by the theoretical UIP relation. Therefore, while we find evidence for a long run equilibrium relationship between the exchange rate and the 


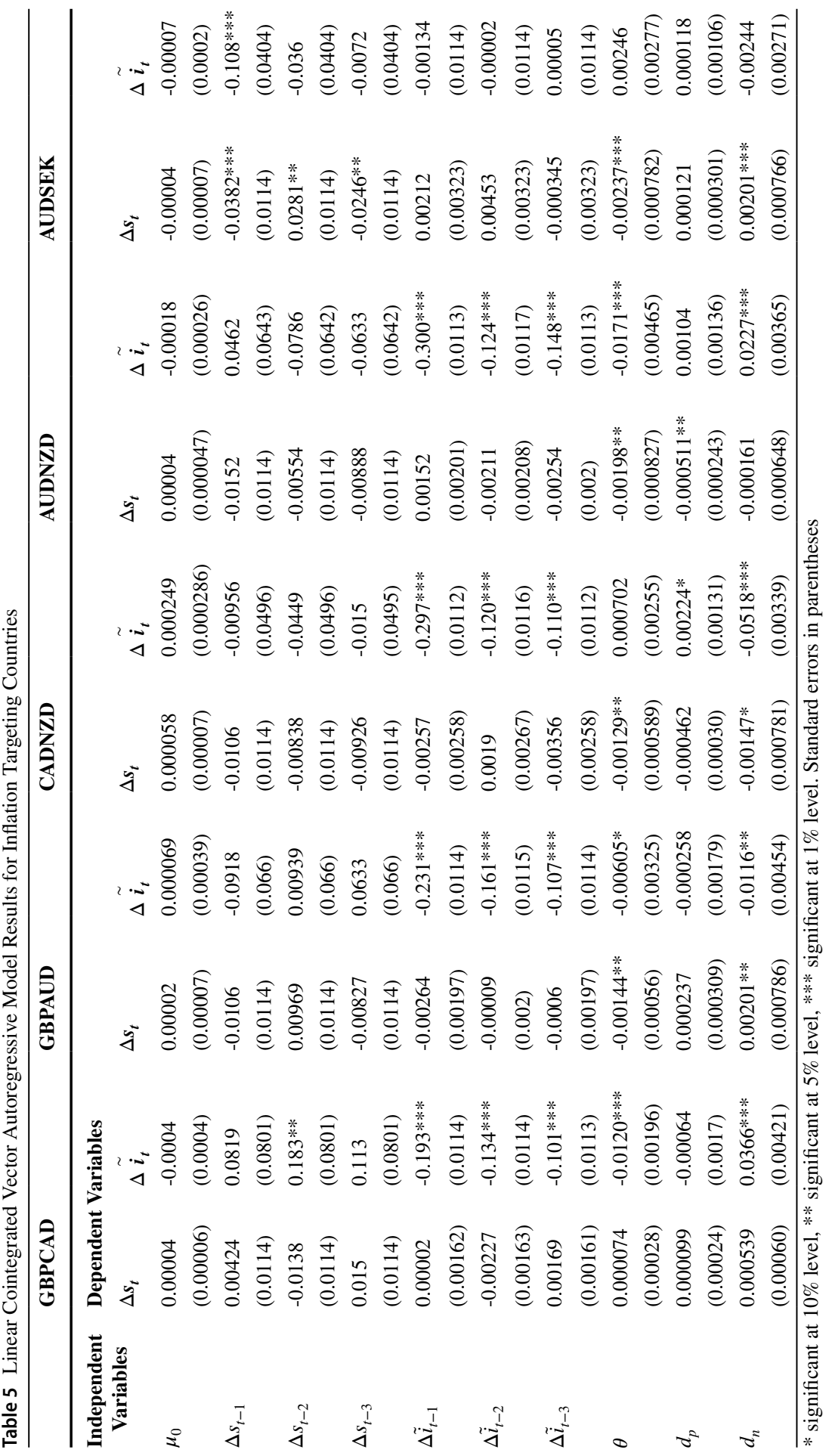




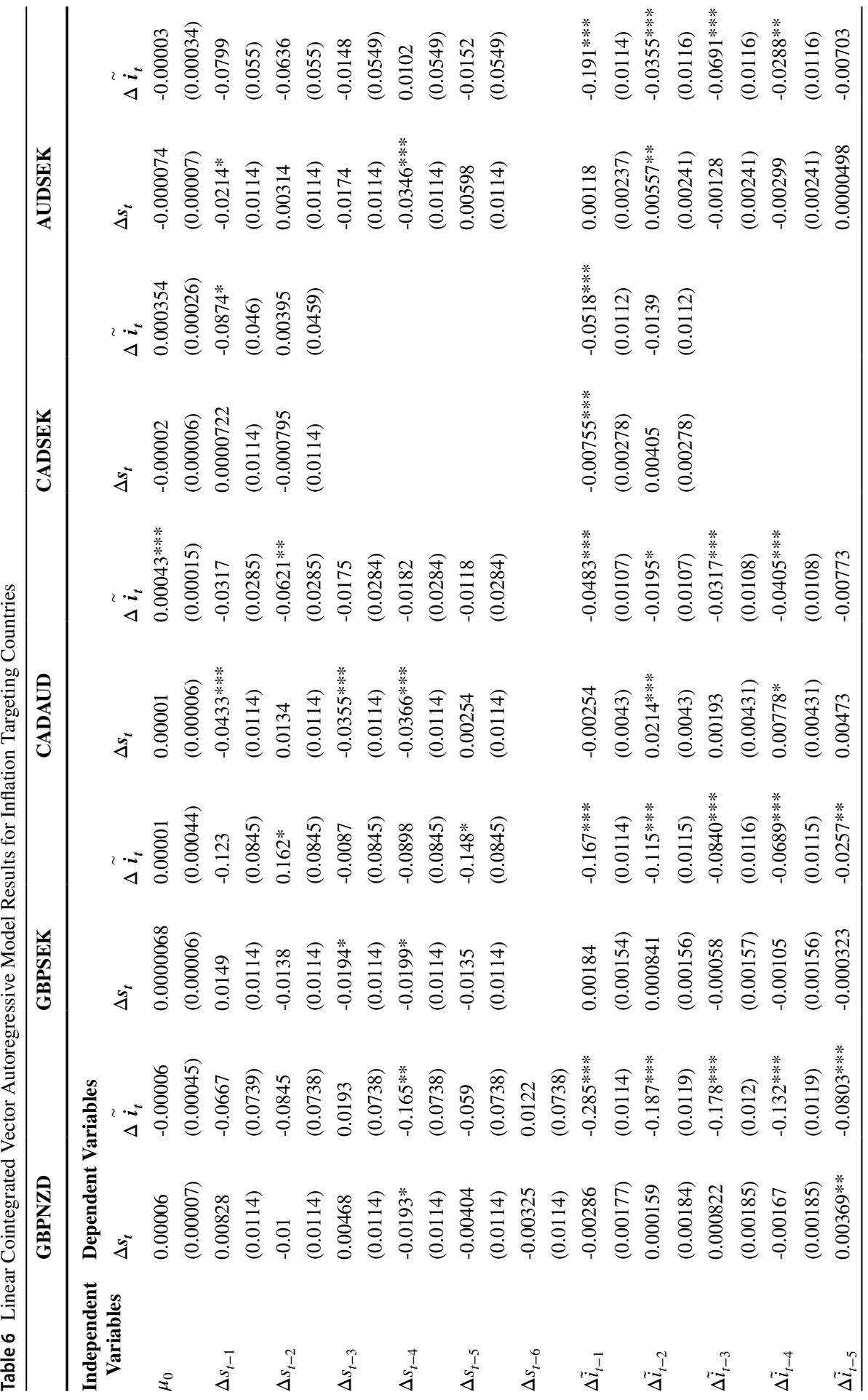




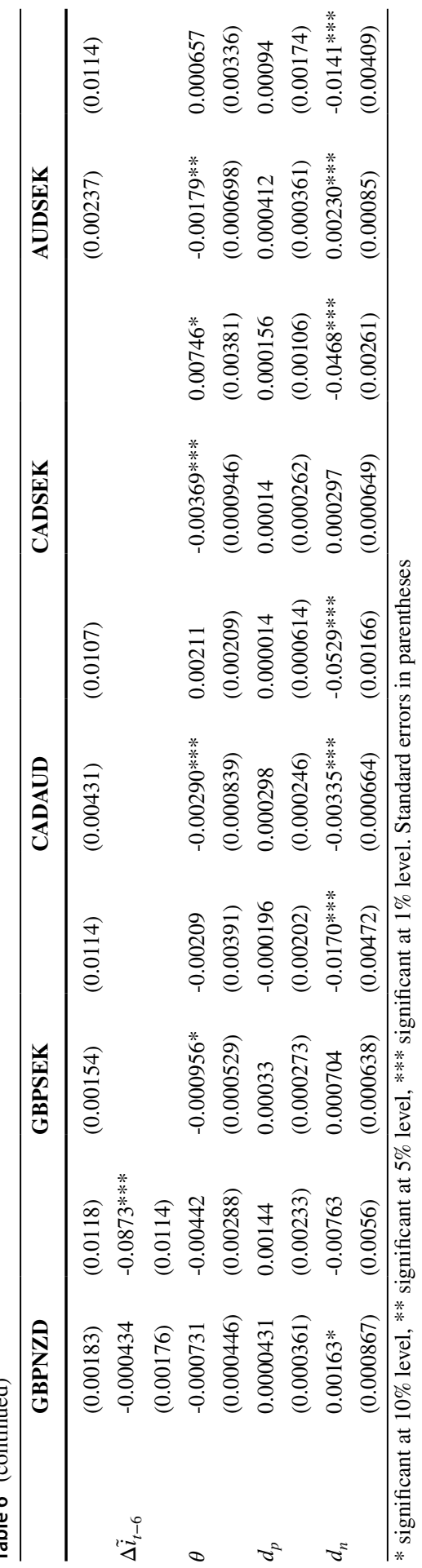


interest rate differential, it is not fully consistent with UIP. ${ }^{1}$ The adjustment speed is low, with a maximum value of $1.7 \%$ for the AUDNZD exchange rate. These findings indicate that deviations from the equilibrium relationship between the exchange rate and the interest rate differential are highly persistent at a daily frequency. In the short run, there is no relation between the exchange rate and the interest rate differential. Central bank announcements of an interest rate decrease generally have a negative effect on the exchange rate (an appreciation) and the interest rate differential. There is no significant difference between inflation targeting countries and the other economies.

Table 7 reports tests of whether the individual variables in the model are at most I(1) or instead I(2) (Juselius 2017). The results show that the former is the case and therefore there can exist an $\mathrm{I}(0)$ cointegrating relationship linking them.

Next we perform a series of diagnostic tests to establish whether the linear model is data congruent. These results are reported in Table 8 and show that none of the models suffer from serial correlation or parameter instability. However, given the finding of a low adjustment speed in the case of the linear models, we perform nonlinearity tests to see whether a nonlinear framework can provide stronger evidence for the existence of an equilibrium relationship between the exchange rate and the interest rate differential both in the short and the long run.

Table 7 Tests for Individual Variable Integration Order in the CVAR

\begin{tabular}{lll}
\hline & \multicolumn{1}{l}{$\boldsymbol{s}_{\boldsymbol{t}}$} & $\tilde{\boldsymbol{i}}_{\boldsymbol{t}}$ \\
\hline GBPCAD & 0.1022 & 0.5813 \\
GBPAUD & 0.6773 & 0.5121 \\
GBPNZD & 0.9192 & 0.6204 \\
GBPSEK & 0.9788 & 0.8629 \\
CADAUD & 0.5311 & 0.9467 \\
CADNZD & 0.8139 & 0.4369 \\
CADSEK & 0.4815 & 0.2042 \\
AUDNZD & 0.4898 & 0.5529 \\
AUDSEK & 0.8103 & 0.9615 \\
NZDSEK & 0.8303 & 0.4896 \\
USDEUR & 0.8433 & 0.8369 \\
USDCHF & 0.3689 & 0.7363 \\
EURCHF & 0.1871 & 0.9140 \\
\hline
\end{tabular}

Hypotheses:

$H_{0}$ : variable is at most I (1)

$H_{1}$ : variable is $I(2)$

$\mathrm{p}$-values reports for all

\footnotetext{
1 We also estimated a trivariate model with the level of the exchange rate, the domestic and the foreign interest rate, and tested the restriction that the two latter variables have equal but opposite coefficients. A LR test confirms that this is a valid restriction and that therefore the bivariate model is appropriate. These results are not reported.
} 
Table 8 Diagnostic Tests for the Linear Models

\begin{tabular}{llll}
\hline & Lag & $\begin{array}{l}\text { Breusch-Godfrey LM Test } \\
\text { for serial correlation }\end{array}$ & $\begin{array}{l}\text { Stability } \\
\text { condition } \\
\text { satisfied }\end{array}$ \\
\hline GBPCAD & 3 & 0.51757 & Stable \\
GBPAUD & 3 & 0.37914 & Stable \\
GBPNZD & 6 & 0.22475 & Stable \\
GBPSEK & 5 & 0.10444 & Stable \\
CADAUD & 5 & 0.20724 & Stable \\
CADNZD & 3 & 0.05954 & Stable \\
CADSEK & 2 & 0.11597 & Stable \\
AUDNZD & 3 & 0.05554 & Stable \\
AUDSEK & 3 & 0.11153 & Stable \\
NZDSEK & 5 & 0.17796 & Stable \\
USDEUR & 3 & 0.28590 & Stable \\
USDCHF & 5 & 0.05062 & Stable \\
EURCHF & 3 & 0.11112 & Stable \\
\hline WE USE & 5 & &
\end{tabular}

We use the Newey-West coefficient covariance matrix Breusch-Godfrey LM Test for serial correlation:

$H_{0}:$ no serial correlation

$H_{1}$ : serial correlation

VAR test for eigenvalue stability conditions. 'Stable' means that all eigenvalues lie inside the unit circle and the model satisfies the stability conditions

\subsection{Nonlinearity Tests and Results of the Smooth Transition Model}

We test for smooth-transition type nonlinearity by means of the Rao F-test; the results are reported in Table 9. The null of linearity is rejected for all models, which confirms that the series exhibit nonlinearities of the smooth transition type. Next we use the EJ selection method for the most appropriate transition function. The results of this test are also included in Table 9 and show in each case whether an exponential or a logistic transition function respectively should be used. Table 10 displays instead the results of the LR test used to determine the lag length for each model.

The estimation results of the nonlinear model are reported in Tables 11 and 12 for the inflation targeting countries, and in Table 13 for the non-targeting ones. Unlike the linear model, the nonlinear one provides some evidence for the existence of a short-run relation between the exchange rate and the interest rate differentials in both regimes. The interest rate differential has a negative effect on the exchange rate in regime one, and a positive one in regime two, while in some countries the exchange rate affects negatively the interest rate differential in regime two. Both positive and negative central bank announcements now influence the exchange rate and the interest rate differential. Interestingly, the effect of central bank announcements on the exchange rate and the interest rate differential switches sign from one regime to the other, i.e. it appears to depend on market expectations of the interest rate. There is 
Table 9 Linearity Test: Rao F-Test; Escribano-Jordá Test and Transition Function

\begin{tabular}{|c|c|c|c|c|}
\hline & & Rao F-Test & Escribano-Jordá Test & Transition function \\
\hline \multirow[t]{2}{*}{ GBPCAD } & Exchange Rate Equation & $0.0000 * * *$ & $0.0000 * * *$ & Exponential \\
\hline & Interest Rate Equation & $0.0000 * * *$ & $0.0000 * * *$ & Logistic \\
\hline \multirow[t]{2}{*}{ GBPAUD } & Exchange Rate Equation & $0.0000 * * *$ & $0.0000 * * *$ & Exponential \\
\hline & Interest Rate Equation & $0.0000 * * *$ & $0.0000 * * *$ & Logistic \\
\hline \multirow[t]{2}{*}{ GBPNZD } & Exchange Rate Equation & $0.0000 * * *$ & $0.0000 * * *$ & Logistic \\
\hline & Interest Rate Equation & $0.0000 * * *$ & $0.0000 * * *$ & Logistic \\
\hline \multirow[t]{2}{*}{ GBPSEK } & Exchange Rate Equation & $0.0000 * * *$ & $0.0000 * * *$ & Exponential \\
\hline & Interest Rate Equation & $0.0000 * * *$ & $0.0000 * * *$ & Logistic \\
\hline \multirow[t]{2}{*}{ CADAUD } & Exchange Rate Equation & $0.0000 * * *$ & $0.0000 * * *$ & Exponential \\
\hline & Interest Rate Equation & $0.0000 * * *$ & $0.0000 * * *$ & Logistic \\
\hline \multirow[t]{2}{*}{ CADNZD } & Exchange Rate Equation & $0.0000 * * *$ & $0.0000 * * *$ & Exponential \\
\hline & Interest Rate Equation & $0.0000 * * *$ & $0.0000 * * *$ & Logistic \\
\hline \multirow[t]{2}{*}{ CADSEK } & Exchange Rate Equation & $0.0000 * * *$ & $0.0000 * * *$ & Logistic \\
\hline & Interest Rate Equation & $0.0000 * * *$ & $0.0000 * * *$ & Exponential \\
\hline \multirow[t]{2}{*}{ AUDNZD } & Exchange Rate Equation & $0.0000 * * *$ & $0.0000 * * *$ & Exponential \\
\hline & Interest Rate Equation & $0.0000 * * *$ & $0.0000 * * *$ & Logistic \\
\hline \multirow[t]{2}{*}{ AUDSEK } & Exchange Rate Equation & $0.0000 * * *$ & $0.0000 * * *$ & Exponential \\
\hline & Interest Rate Equation & $0.0000 * * *$ & $0.0000 * * *$ & Exponential \\
\hline \multirow[t]{2}{*}{ NZDSEK } & Exchange Rate Equation & $0.0000 * * *$ & $0.0000 * * *$ & Exponential \\
\hline & Interest Rate Equation & $0.0000 * * *$ & $0.0000 * * *$ & Logistic \\
\hline \multirow[t]{2}{*}{ USDEUR } & Exchange Rate Equation & $0.0000 * * *$ & $0.0000 * * *$ & Logistic \\
\hline & Interest Rate Equation & $0.0000 * * *$ & $0.0000 * * *$ & Logistic \\
\hline \multirow[t]{2}{*}{ USDCHF } & Exchange Rate Equation & $0.0000 * * *$ & $0.0000 * * *$ & Exponential \\
\hline & Interest Rate Equation & $0.0000 * * *$ & $0.0000 * * *$ & Exponential \\
\hline \multirow[t]{2}{*}{ EURCHF } & Exchange Rate Equation & $0.0000 * * *$ & $0.0000 * * *$ & Exponential \\
\hline & Interest Rate Equation & $0.0000 * * *$ & $0.0000 * * *$ & Logistic \\
\hline \multicolumn{3}{|c|}{$\begin{array}{l}* * * \text { significant at } 1 \% . \text { P-values reported } \\
\text { Rao-F Test: } \\
H_{0}: \text { linearity } \\
H_{1}: \text { smooth - transition nonlinearity }\end{array}$} & \multicolumn{2}{|c|}{$\begin{array}{l}\text { Escribano-Jordá Test: } \\
\text { Logistic Transition Function: } \\
H_{0_{L}}: \beta_{2}^{\prime}=\beta_{4}^{\prime}=0 \\
H_{1_{L}}: \beta_{2}^{\prime} \neq \beta_{4}^{\prime} \neq 0 \\
\text { Exponential Transition Function: } \\
H_{0_{L}}: \beta_{1}^{\prime}=\beta_{3}^{\prime}=0 \\
H_{1_{L}}: \beta_{1}^{\prime} \neq \beta_{3}^{\prime} \neq 0\end{array}$} \\
\hline
\end{tabular}

less evidence for a short-run relation between the exchange rate and the interest rate differential in non-targeting economies.

Table 14 provides information about the transition function, specifically the transition parameter $c$ and the smoothness parameter $\gamma$, and also reports the estimates of the $\theta$ coefficient (the speed of adjustment) for the two regimes-this the optimal number of regimes which is selected in all cases by using as a criterion the minimum sum of squared residuals. Graphs for the corresponding transition functions 
Table 10 Lag Selection for the STCVAR Model

\begin{tabular}{|c|c|c|c|c|c|c|c|}
\hline Lag & GBPCAD & GBPAUD & GBPNZD & GBPSEK & CADAUD & CADNZD & CADSEK \\
\hline 1 & 22.12 & 77.1 & 23.6 & 17.7 & 6.96 & 4.32 & $5.86^{*}$ \\
\hline 2 & 19.48 & 6.14 & 16.16 & $6.52 *$ & 54.62 & 0.56 & 11.08 \\
\hline 3 & $6.8^{*}$ & $32.4 *$ & 24.17 & 0.18 & $33.38 *$ & $9.32 *$ & 0.98 \\
\hline 4 & 3.18 & 59.18 & $10.70 *$ & 3.88 & 4.74 & 2.7 & 3.66 \\
\hline 5 & 4.06 & 25.12 & 8.724 & 2.46 & 0.56 & 9 & 3.08 \\
\hline 6 & 22.12 & 77.1 & 23.6 & 17.7 & 6.96 & 4.32 & 5.86 \\
\hline Lag & AUDNZD & AUDSEK & NZDSEK & USDEUR & USDCHF & EURCHF & \\
\hline 1 & 14.04 & 129.84 & 16.28 & 5.5 & 6.62 & $7.46^{*}$ & \\
\hline 2 & 3.96 & 13.86 & 13.12 & $19.38^{*}$ & $15.98 *$ & 4.98 & \\
\hline 3 & $8.02 *$ & $31.14^{*}$ & $10.42 *$ & 42.7 & 8.7 & 97.74 & \\
\hline 4 & 6.18 & 16.52 & 4.9 & 13.8 & 0.82 & 97.58 & \\
\hline 5 & 8.5 & 8.56 & 0.06 & 18.4 & 93.62 & 6.82 & \\
\hline 6 & 14.04 & 129.84 & 16.28 & 5.5 & 6.62 & 7.46 & \\
\hline
\end{tabular}

Likelihood Ratio Test: sequential modified LR test statistic at 5\%

* indicates the chosen lag at which there exists no serial correlation

are included in the Appendix Figs. 1, 2, 3, 4, 5, 6, 7, 8, 9, 10, 11, 12, 13, 14, 15, 16, $17,18,19,20,21,22,23,24,25,26$.

It can be seen that the adjustment speed in the nonlinear model is substantially faster than in the linear one: between 10 and $43 \%$ of any deviations from the equilibrium is corrected within one day, which means that a nonlinear framework provides stronger evidence than a linear one in support of a long-run equilibrium relationship between the exchange rate and the interest rate differential. While the adjustment occurs in both the interest rate and the exchange rate equations, the speed is substantially faster in the case of the former. These findings imply that it is the interest rate differential (rather than the exchange rate) which adjusts to restore the equilibrium. The adjustment is particularly fast in regime two, i.e. when the change in the expected interest rate exceeds the transition value $c$. This suggests that the equilibrium relationship between the exchange rate and the interest rate differential generally holds better when interest rates are expected to increase. Evidence for error-increasing behaviour could be found in only one exchange rate equation (GBPNZD) and in regime 1 for some interest rate equations (for instance GBPAUD, GBPNZD, GBPSEK, CADAUD, AUDNZD). The positive coefficient in regime one in some equations indicates that deviations from the long-run equilibrium relationship between the exchange rate and the interest rate differential are persistent when the market expects the interest rate to fall in the near future. On average the non-targeting economies seem to be characterised by a lower adjustment speed than the inflation targeting ones, which suggests that interest rate expectations play a more important role in the adjustment towards the long-run equilibrium under inflation targeting. On the whole, the results in Table 15 indicate that the system moves back towards its long-run equilibrium through adjustments in the interest rate equation, but only when 


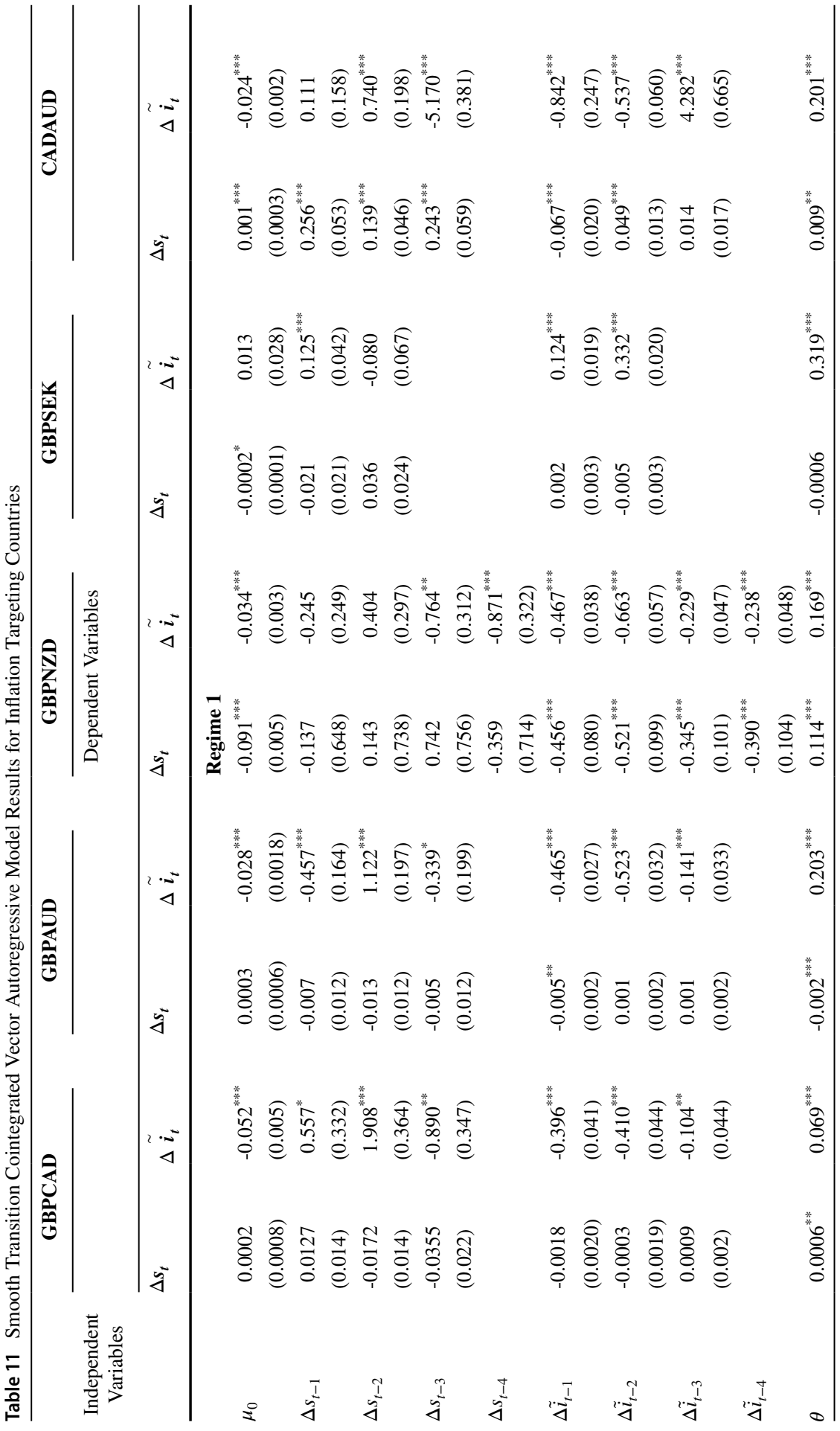




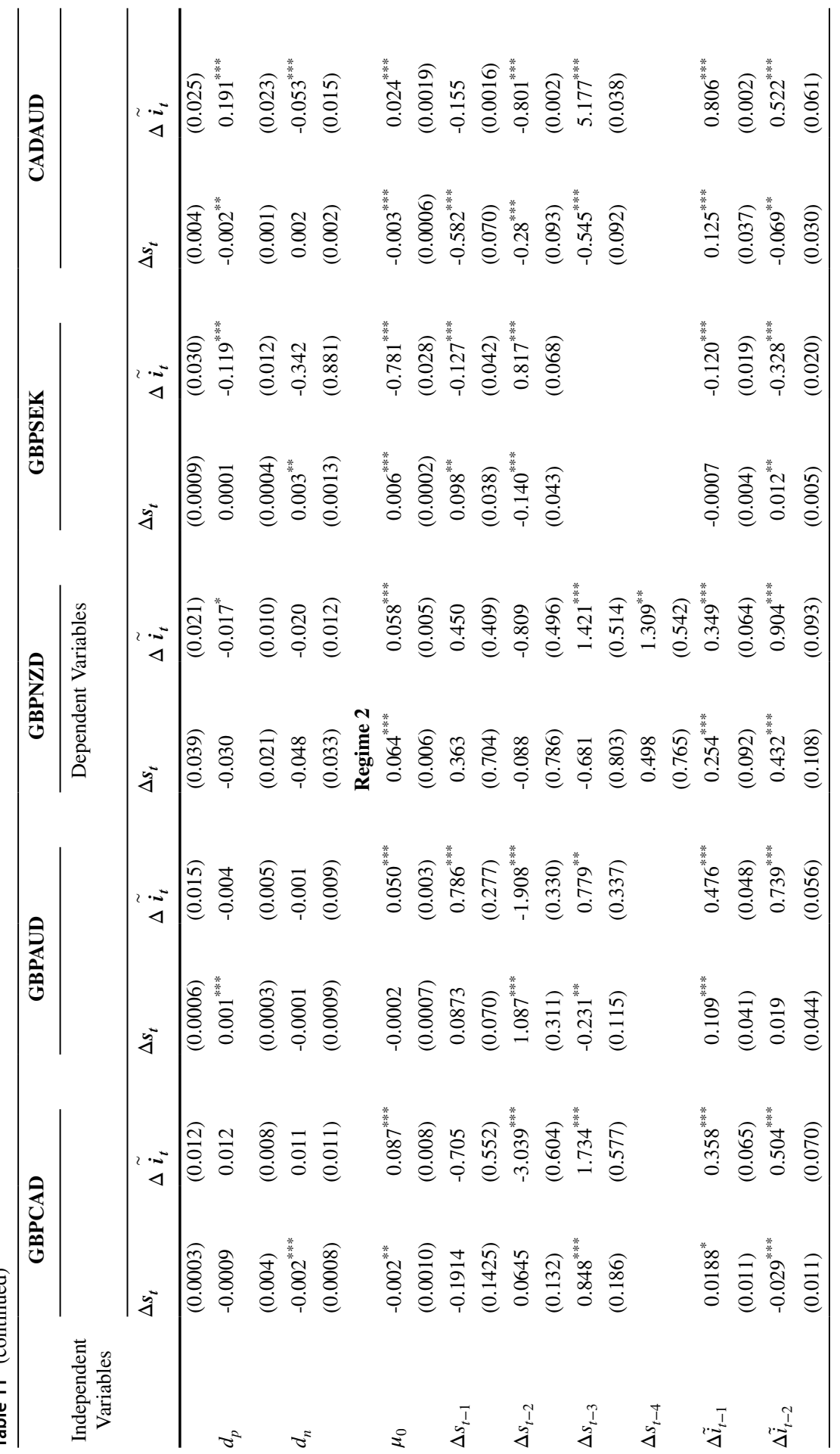




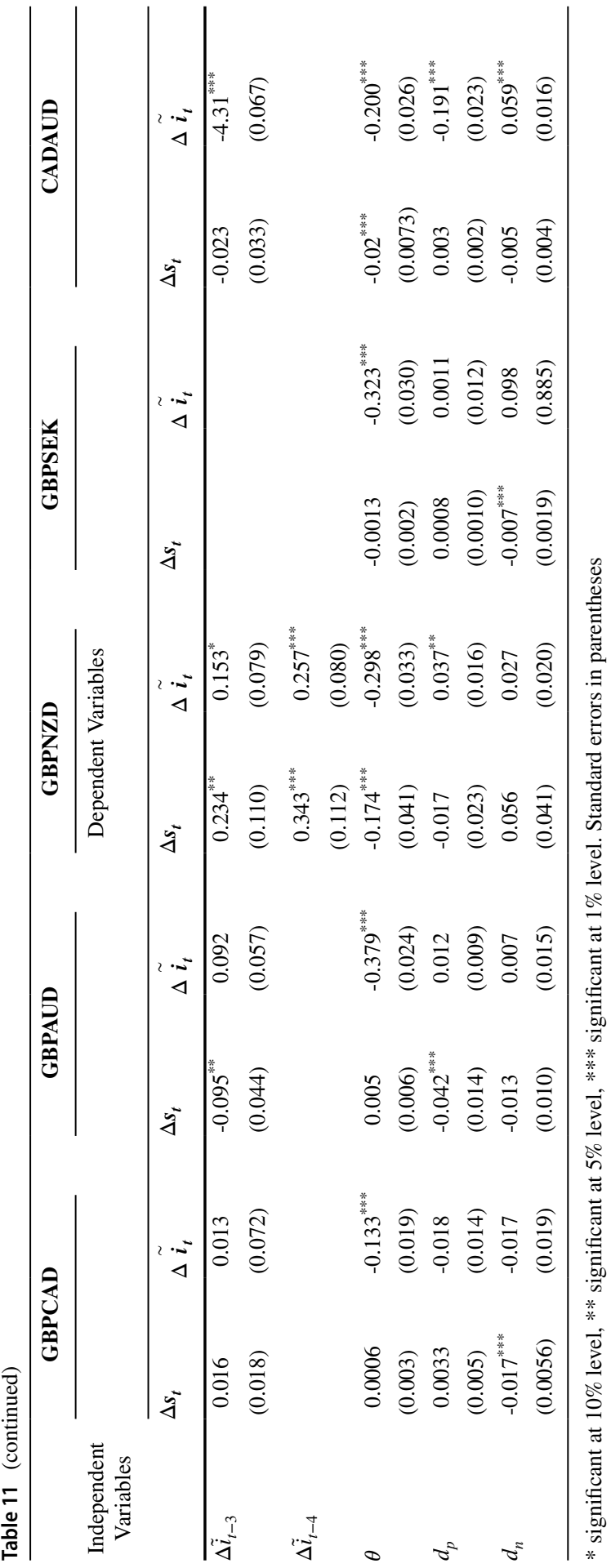




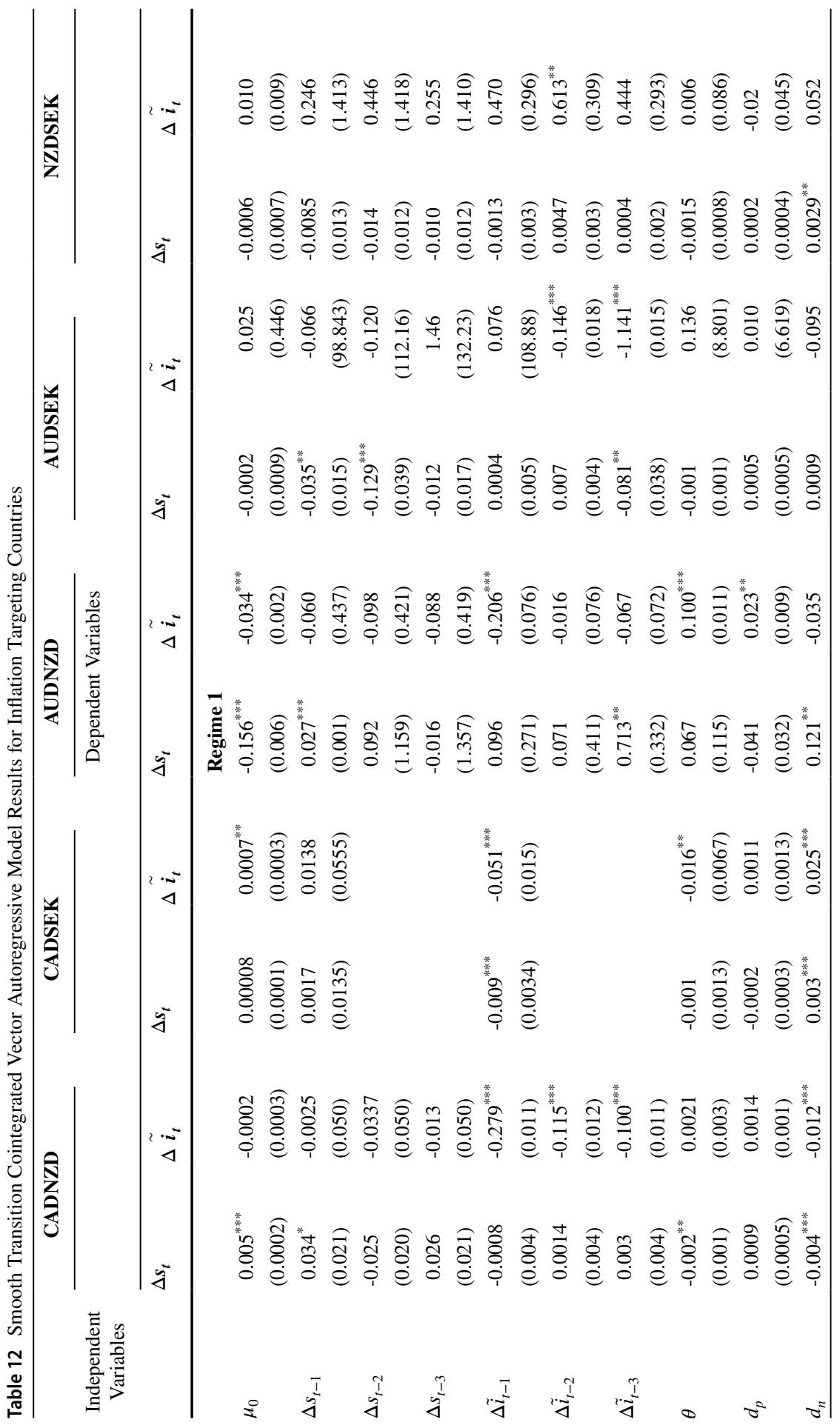




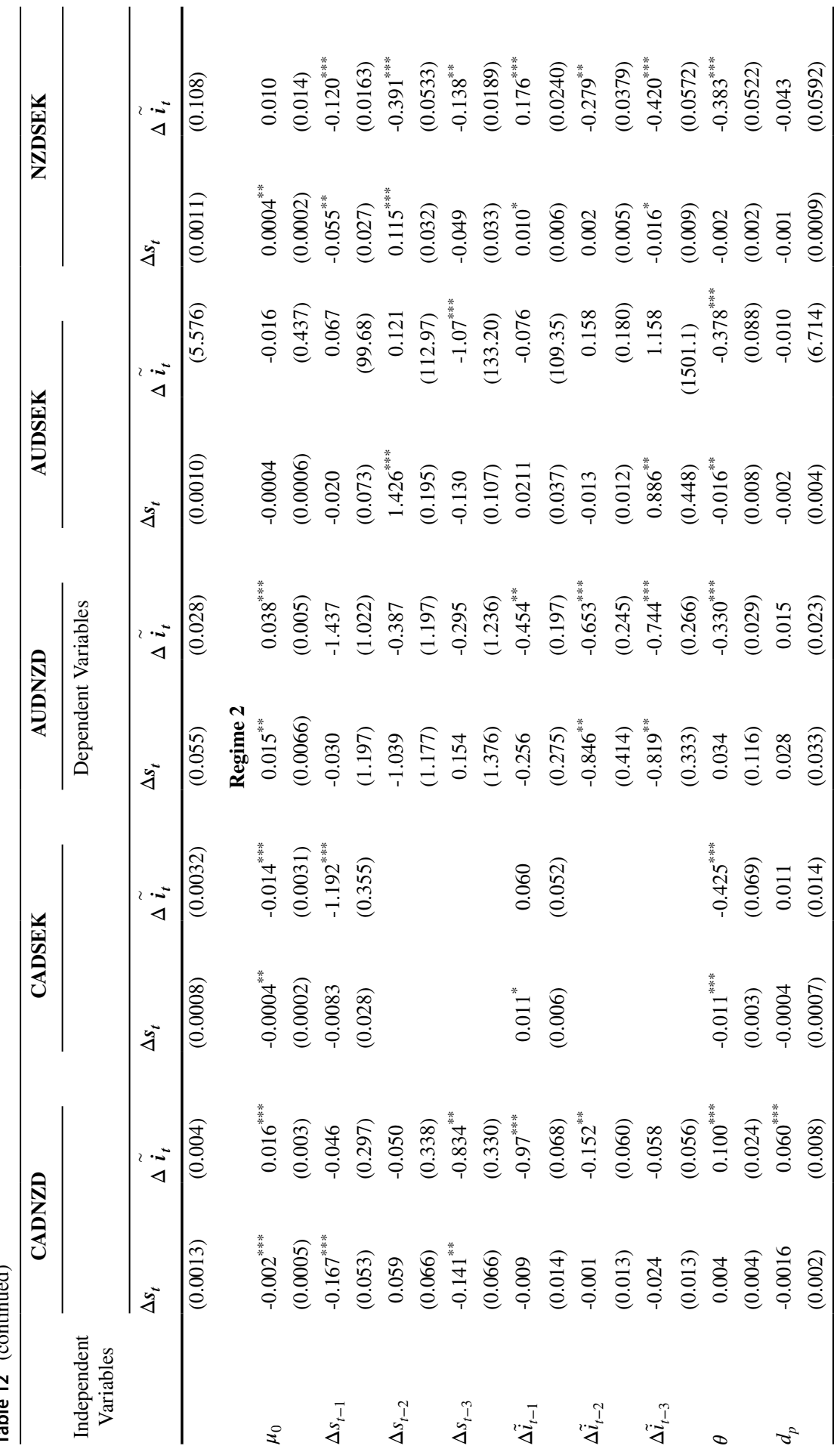




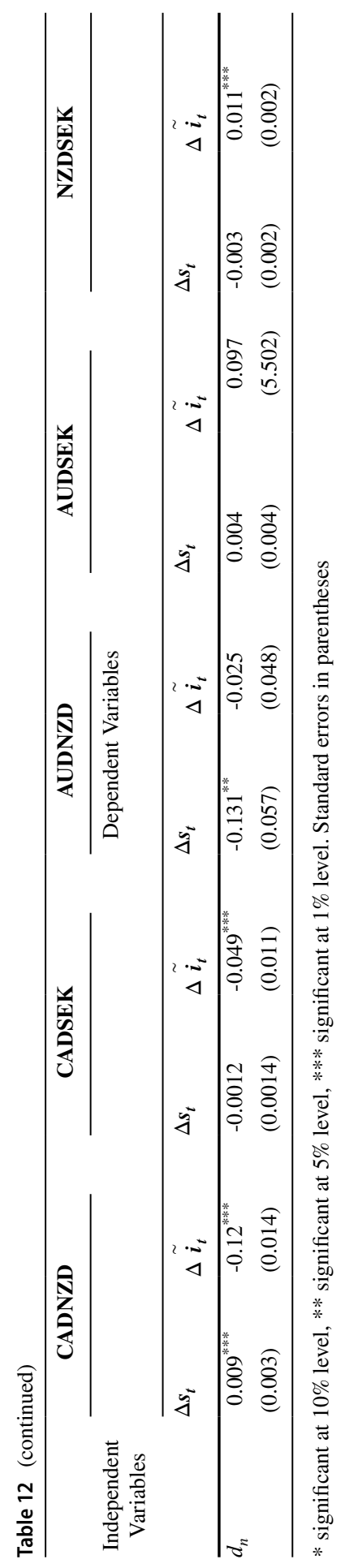

照 Springer 
Table 13 Smooth Transition Cointegrated Vector Autoregressive Model Results for Non-Targeting Economies

\begin{tabular}{|c|c|c|c|c|c|c|}
\hline & USDEUR & & USDCHF & & EURCHF & \\
\hline Independent & Dependent & riables & & & & \\
\hline Variables & $\Delta s_{t}$ & $\Delta \tilde{i}_{t}$ & $\Delta s_{t}$ & $\Delta \tilde{i}_{t}$ & $\Delta s_{t}$ & $\Delta \tilde{i}_{t}$ \\
\hline Regime 1 & & & & & & \\
\hline$\mu_{0}$ & 0.0001 & 0.0001 & 0.0002 & -0.0012 & -0.00005 & 0.0016 \\
\hline & $(0.0002)$ & $(0.0002)$ & $(0.0002)$ & $(0.0030)$ & $(0.00005)$ & $(0.0019)$ \\
\hline$\Delta s_{t-1}$ & $0.073^{* * *}$ & 0.0022 & $-0.087^{*}$ & -0.0829 & -0.0038 & 0.6241 \\
\hline & $(0.0278)$ & $(0.0454)$ & $(0.0346)$ & $(0.6158)$ & $(0.0220)$ & $(0.6668)$ \\
\hline$\Delta s_{t-2}$ & -0.026 & $0.077^{*}$ & -0.029 & -0.236 & & \\
\hline & $(0.0316)$ & $(0.0454)$ & $(0.0271)$ & $(0.4513)$ & & \\
\hline$\Delta \tilde{i}_{t-1}$ & -0.009 & $0.049^{* * *}$ & 0.0006 & 0.0112 & -0.0003 & $-0.2498^{* * *}$ \\
\hline & $(0.0059)$ & $(0.0110)$ & $(0.0007)$ & $(0.0397)$ & $(0.00032)$ & $(0.0113)$ \\
\hline$\Delta \tilde{i}_{t-2}$ & -0.008 & $-0.103^{* * *}$ & 0.0001 & 0.0119 & & \\
\hline & $(0.0055)$ & $(0.0106)$ & $(0.0007)$ & $(0.0296)$ & & \\
\hline$\theta$ & -0.0003 & -0.0004 & -0.0009 & $-0.032^{* * * *}$ & 0.00014 & $-0.0764^{* * *}$ \\
\hline & $(0.0002)$ & $(0.0004)$ & $(0.0007)$ & $(0.0042)$ & $(0.00015)$ & $(0.0053)$ \\
\hline$d_{p}$ & $0.0025^{\text {*** }}$ & -0.0010 & $0.0034^{* * *}$ & -0.025 & -0.00057 & -0.0095 \\
\hline & $(0.0009)$ & $(0.0013)$ & $(0.0013)$ & $(0.0363)$ & $(0.00036)$ & $(0.0137)$ \\
\hline$d_{n}$ & $0.0041^{\text {*** }}$ & $-0.024^{* * *}$ & 0.0002 & 0.0283 & 0.00025 & -0.0177 \\
\hline & $(0.0016)$ & $(0.0036)$ & $(0.0016)$ & $(0.070)$ & $(0.0008)$ & $(0.0245)$ \\
\hline Regime 2 & & & & & & \\
\hline$\mu_{0}$ & -0.0001 & -0.476 & $0.0009^{* *}$ & 0.0007 & $0.00030^{* *}$ & $-0.0627^{* * *}$ \\
\hline & $(0.0002)$ & $(0.398)$ & $(0.0004)$ & $(0.0038)$ & $(0.00013)$ & $(0.0102)$ \\
\hline$\Delta s_{t-1}$ & $-0.110^{* * *}$ & -0.880 & $0.244^{* * *}$ & 0.267 & $0.2617^{* * *}$ & -0.768 \\
\hline & $(0.0398)$ & $(68.548)$ & $(0.0461)$ & $(0.7336)$ & $(0.0326)$ & (1.3224) \\
\hline$\Delta s_{t-2}$ & 0.047 & -0.628 & 0.089 & 0.296 & & \\
\hline & $(0.0456)$ & $(66.942)$ & $(0.0584)$ & $(0.6625)$ & & \\
\hline$\Delta \tilde{i}_{t-1}$ & 0.012 & -1.775 & -0.0004 & $-0.504^{* * *}$ & 0.00089 & $-0.1999^{* * *}$ \\
\hline & $(0.0076)$ & $(1.5558)$ & & & & \\
\hline$\Delta \tilde{i}_{t-2}$ & 0.011 & -1.40 & -0.0007 & $-0.276^{* * *}$ & & \\
\hline & $(0.0076)$ & $(1.1302)$ & $(0.0014)$ & $(0.0322)$ & & \\
\hline$\theta$ & 0.0004 & $-0.209^{* * *}$ & 0.0009 & $-0.132^{* * *}$ & $-0.0008^{* * *}$ & $-0.1815^{* * *}$ \\
\hline & $(0.0003)$ & $(0.016)$ & $(0.0016)$ & $(0.0050)$ & $(0.00035)$ & $(0.0264)$ \\
\hline$d_{p}$ & $-0.006^{* * *}$ & -0.660 & $-0.008^{* * *}$ & 0.0203 & $0.0019^{* *}$ & $0.1779^{* * * *}$ \\
\hline & $(0.0013)$ & $(0.6038)$ & $(0.0023)$ & $(0.0396)$ & $(0.0008)$ & $(0.0496)$ \\
\hline$d_{n}$ & $-0.005^{* *}$ & 1.470 & $0.0041^{*}$ & -0.0284 & -0.00001 & 0.1198 \\
\hline & $(0.0022)$ & $(0.9988)$ & $(0.0025)$ & $(0.070)$ & $(0.0012)$ & $(0.1135)$ \\
\hline
\end{tabular}

* significant at $10 \%$ level, ** significant at 5\% level, *** significant at $1 \%$ level. Standard errors in parentheses

the market expects the central bank to adopt a contractionary monetary policy stance by raising the interest rate in the near future. 
Table 14 Smooth Transition Model Regimes

\begin{tabular}{|c|c|c|c|c|c|}
\hline & \multirow[b]{2}{*}{ Equation } & \multicolumn{2}{|l|}{ Regimes } & \multicolumn{2}{|l|}{ Transition } \\
\hline & & $\begin{array}{l}\text { Regime 1: } \\
\theta\end{array}$ & $\begin{array}{l}\text { Regime 2: } \\
\theta \bullet G_{t}\end{array}$ & $c$ & $\gamma$ \\
\hline \multirow[t]{2}{*}{ GBPCAD } & $\Delta s_{t}$ & $0.0006^{* *}$ & 0.0006 & -0.055868 & 14.78672 \\
\hline & $\Delta \tilde{i}_{t}$ & $0.069^{* * *}$ & $-0.133^{* * *}$ & -0.016814 & 22.65341 \\
\hline \multirow[t]{2}{*}{ GBPAUD } & $\Delta s_{t}$ & $-0.002^{* * *}$ & 0.005 & -0.005186 & 13.16741 \\
\hline & $\Delta \tilde{i}_{t}$ & $0.203^{* * *}$ & $-0.379^{* * *}$ & -0.006006 & 45.75886 \\
\hline \multirow[t]{2}{*}{ GBPNZD } & $\Delta s_{t}$ & $0.114^{* * *}$ & $-0.174^{* * *}$ & -0.012500 & 62.36919 \\
\hline & $\Delta \tilde{i}_{t}$ & $0.169^{* * *}$ & $-0.298^{* * *}$ & -0.012345 & 31.67953 \\
\hline \multirow[t]{2}{*}{ GBPSEK } & $\Delta s_{t}$ & -0.0006 & -0.0013 & 0.020142 & 65.02806 \\
\hline & $\Delta \tilde{i}_{t}$ & $0.319^{* * *}$ & $-0.323^{* * *}$ & -0.272267 & 66.07738 \\
\hline \multirow[t]{2}{*}{ CADAUD } & $\Delta s_{t}$ & $0.009^{* *}$ & $-0.02^{* * *}$ & -0.173465 & 21.68449 \\
\hline & $\Delta \tilde{i}_{t}$ & $0.201^{* * *}$ & $-0.200^{* * *}$ & -0.192480 & 15.45625 \\
\hline \multirow[t]{2}{*}{ CADNZD } & $\Delta s_{t}$ & $-0.002^{* *}$ & 0.004 & -0.050491 & 85.06376 \\
\hline & $\Delta \tilde{i}_{t}$ & 0.0021 & $0.100^{* * *}$ & 0.081161 & 18.91247 \\
\hline \multirow[t]{2}{*}{ CADSEK } & $\Delta s_{t}$ & -0.001 & $-0.011^{* * *}$ & 0.009453 & 42.40906 \\
\hline & $\Delta \tilde{i}_{t}$ & $-0.016^{* *}$ & $-0.425^{* * *}$ & 0.047907 & 16.40401 \\
\hline \multirow[t]{2}{*}{ AUDNZD } & $\Delta s_{t}$ & 0.067 & 0.034 & -0.088433 & 88.81159 \\
\hline & $\Delta \tilde{i}_{t}$ & $0.100^{* * *}$ & $-0.330^{* * *}$ & 0.014948 & 46.41960 \\
\hline \multirow[t]{2}{*}{ AUDSEK } & $\Delta s_{t}$ & -0.001 & $-0.016^{* *}$ & -0.107431 & 8.321685 \\
\hline & $\Delta \tilde{i}_{t}$ & 0.136 & $-0.378^{* * *}$ & 0.135389 & 2.311828 \\
\hline \multirow[t]{2}{*}{ NZDSEK } & $\Delta s_{t}$ & -0.0015 & -0.002 & 0.010824 & 13.86116 \\
\hline & $\Delta \tilde{i}_{t}$ & 0.006 & $-0.383^{* * *}$ & 2.131533 & 31.05755 \\
\hline \multirow[t]{2}{*}{ USDEUR } & $\Delta s_{t}$ & -0.0003 & 0.0004 & -0.001864 & 34.44399 \\
\hline & $\Delta \tilde{i}_{t}$ & -0.0004 & $-0.209^{* * *}$ & 0.162205 & 26.28246 \\
\hline \multirow[t]{2}{*}{ USDCHF } & $\Delta s_{t}$ & -0.0009 & 0.0009 & -0.018740 & 12.51957 \\
\hline & $\Delta \tilde{i}_{t}$ & $-0.032^{* * *}$ & $-0.132^{* * *}$ & 0.000023 & 1.940000 \\
\hline \multirow[t]{2}{*}{ EURCHF } & $\Delta s_{t}$ & 0.00014 & $-0.0008^{* *}$ & 0.003511 & 67.78872 \\
\hline & $\Delta \tilde{i}_{t}$ & $-0.0764^{* * * *}$ & $-0.1815^{* * *}$ & 0.016260 & 17.30912 \\
\hline
\end{tabular}

Transition variable $z_{t}$ : change in the 30 -day interest rate

$\theta$ is the speed of adjustment parameter in regime $1 ; \theta \bullet G_{t}$ is the speed of adjustment parameter in regime $2 ; \mathrm{c}$ is the transition value, which indicates where the transition takes place; and $\gamma$ is the smoothness parameter which indicates the speed of transition

Finally, to check the adequacy of the nonlinear STCVAR model we conduct Lagrange Multiplier (LM) Tests of serial correlation, of no remaining nonlinearity and of parameter constancy. The test statistics are reported in Table 15 and confirm the data congruency of the nonlinear specification. In particular, there is no evidence 
Table 15 Misspecification Tests for the Nonlinear STCVAR Models

\begin{tabular}{lllll}
\hline & Lag & $\begin{array}{l}\text { Serial } \\
\text { Independence }\end{array}$ & No remaining nonlinearity & $\begin{array}{l}\text { Parameter } \\
\text { constancy }\end{array}$ \\
\hline GBPCAD & 3 & 0.5916 & 0.1141 & 0.0531 \\
GBPAUD & 3 & 0.9698 & 0.1629 & 0.1800 \\
GBPNZD & 4 & 0.1462 & 0.7581 & 0.1623 \\
GBPSEK & 2 & 0.6140 & 0.1560 & 0.3158 \\
CADAUD & 3 & 0.5677 & 0.1083 & 0.4600 \\
CADNZD & 3 & 0.9876 & 0.7039 & 0.1369 \\
CADSEK & 1 & 0.7790 & 0.8870 & 0.9510 \\
AUDNZD & 3 & 0.7638 & 0.6959 & 0.0762 \\
AUDSEK & 3 & 0.7067 & 0.4491 & 0.3835 \\
NZDSEK & 3 & 0.2819 & 0.0704 & 0.1590 \\
USDEUR & 2 & 0.3147 & 0.2530 & 0.1393 \\
USDCHF & 2 & 0.9187 & 0.2895 & 0.1517 \\
EURCHF & 1 & 0.5752 & 0.2070 & 0.2442 \\
\hline Lagrange Multiplier $($ LM) Test of serial correlation: & & Lagrange Multiplier (LM) test of \\
$H_{0}:$ no serial correlation & & & $H_{0}:$ parameter constancy & \\
$H_{1}:$ serial correlation & & & $H_{1}:$ no parameter constancy \\
Lagrange Multiplier $($ LM) test of no remaining nonlinear- & & \\
ity: $H_{0}:$ no remaining nonlinearity & & & &
\end{tabular}

of an impact of the recent COVID-19 pandemic, which is known to have affected other financial markets (e.g., Salisu and Vo 2020).

To assess the importance of the announcement dummies we compare the nonlinear STCVAR model with one from which the central bank announcement dummies are excluded. These results are reported in Tables 16, 17 and 18 and indicate that the adjustment speed tends to be lower when excluding the dummies from the model. Therefore accounting for central bank announcements of changes in the interest rate therefore seems to be important for understanding how interest rate expectations influence the adjustment towards the equilibrium relationship between the exchange rate and the interest rate differential.

It is also important to provide evidence that the chosen transition variables are in fact suitable. Table 19 compares the adjustment speed of the original model, which includes the change in the 30-day interest rate as a transition variable, with those from models with alternative transition variables. As can be seen, the highest speed is estimated in the case of the specification including the 30-day interest rate as the transition variable. 


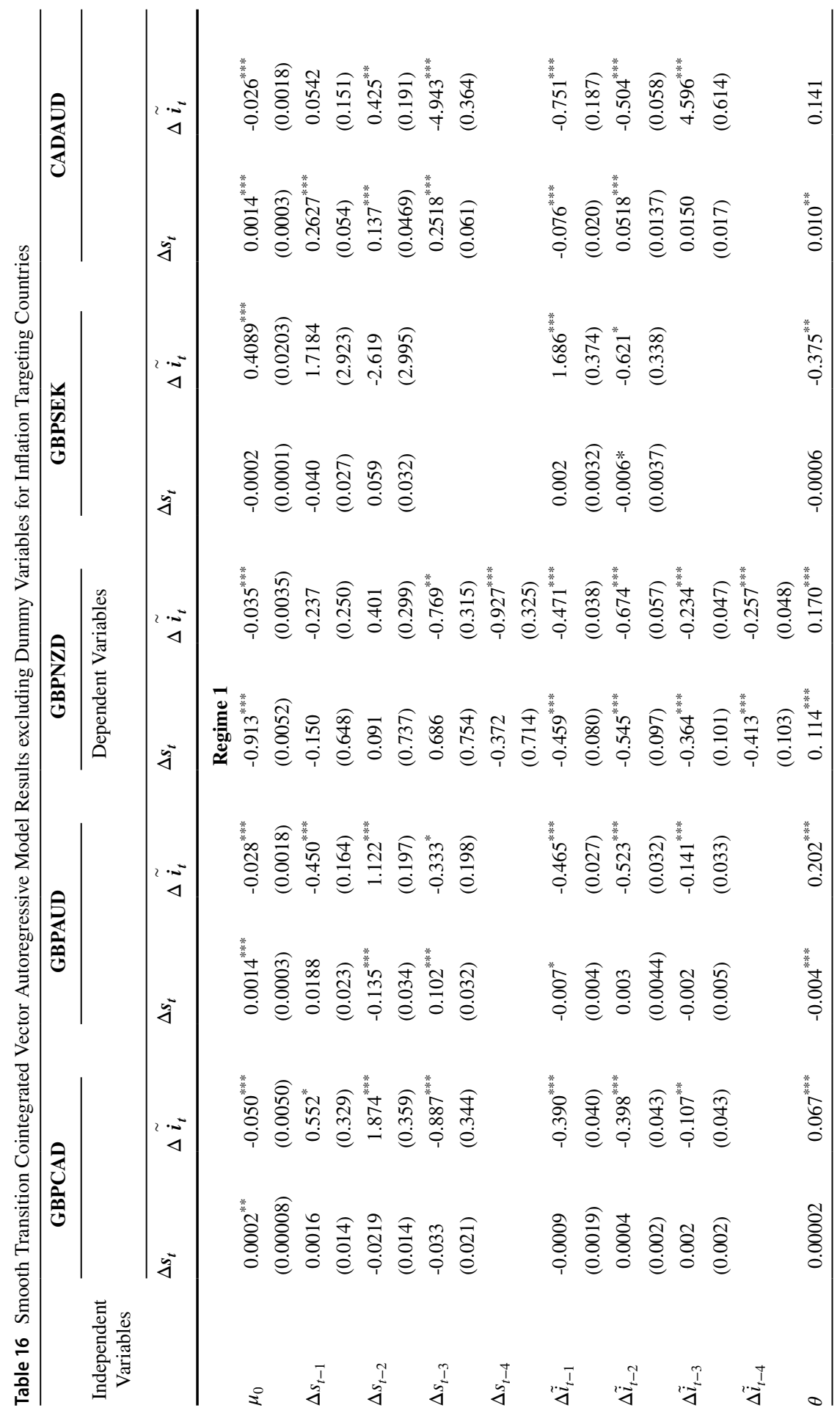




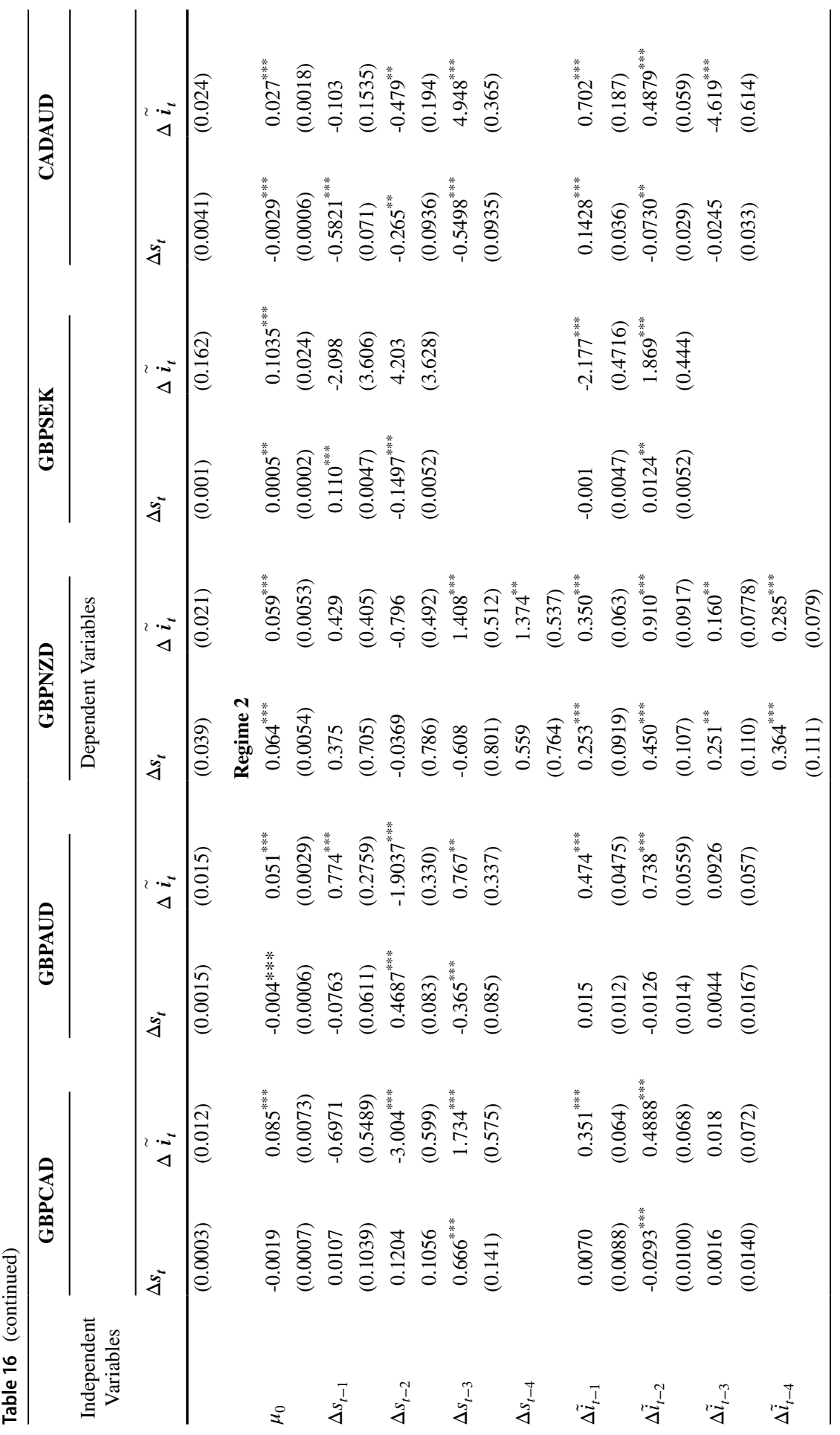




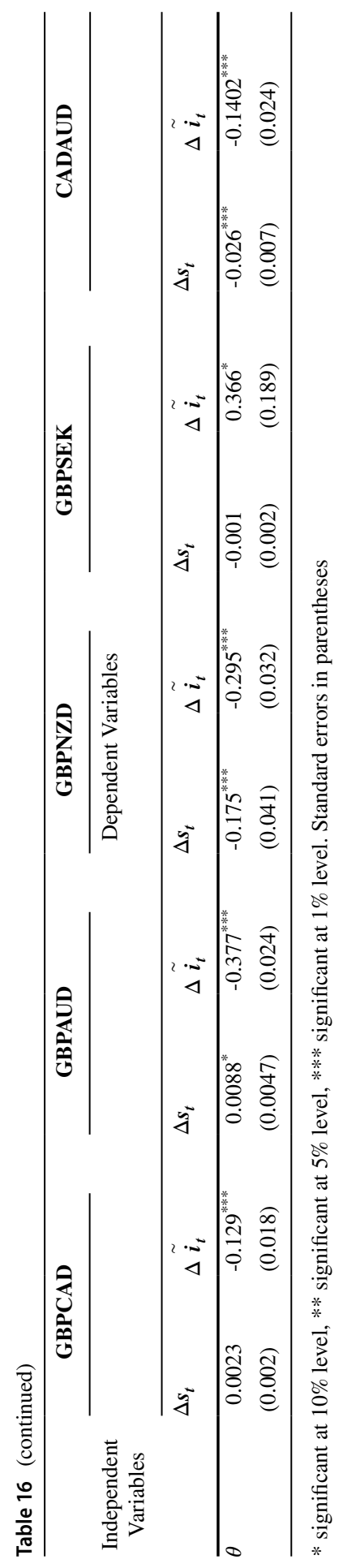

를 Springer 


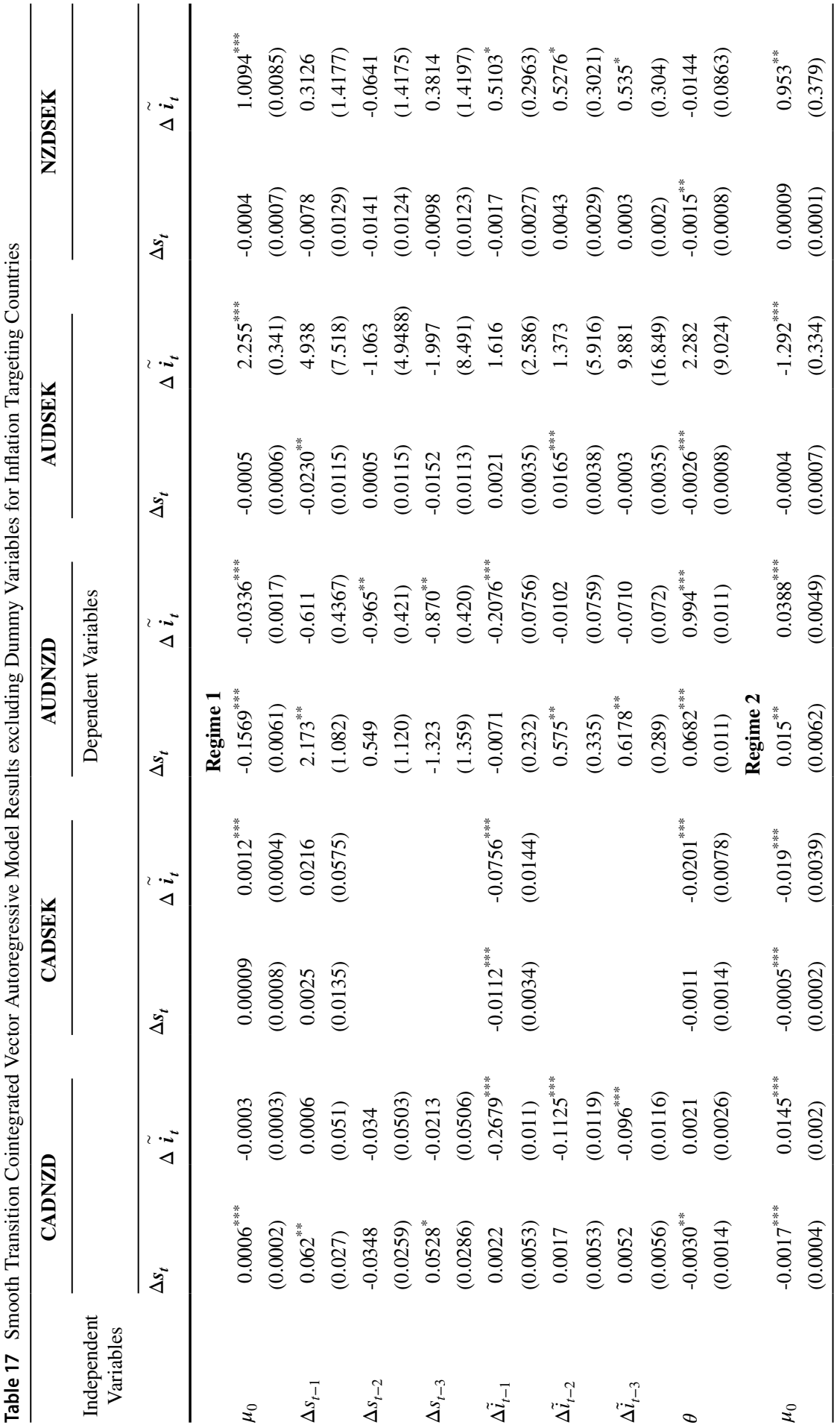




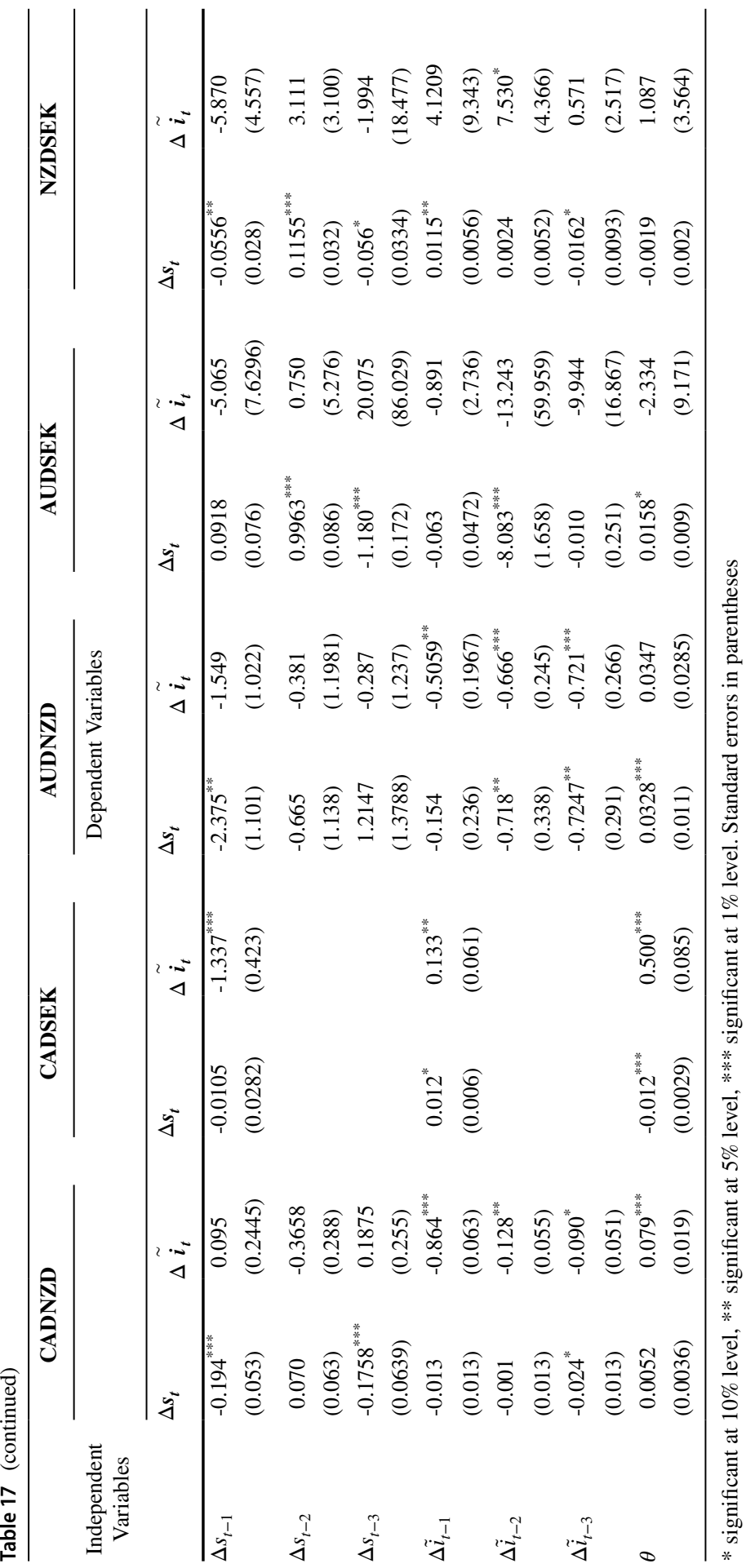


Table 18 Smooth Transition Cointegrated Vector Autoregressive Model Results excluding Dummy Variables for Non-Targeting Economies

\begin{tabular}{|c|c|c|c|c|c|c|}
\hline & USDEUR & & USDCHF & & EURCHF & \\
\hline Independent & Dependen & riables & & & & \\
\hline Variables & $\Delta s_{t}$ & $\Delta \tilde{i}_{t}$ & $\Delta s_{t}$ & $\Delta \tilde{i}_{t}$ & $\Delta s_{t}$ & $\Delta \tilde{i}_{t}$ \\
\hline Regime 1 & & & & & & \\
\hline$\mu_{0}$ & $\begin{array}{l}0.0004^{*} \\
(0.0002)\end{array}$ & $\begin{array}{l}0.00005 \\
(0.0002)\end{array}$ & $\begin{array}{l}0.0005 \\
(0.0007)\end{array}$ & $\begin{array}{l}-0.0017 \\
(0.0033)\end{array}$ & $\begin{array}{l}-0.00005 \\
(0.00005)\end{array}$ & $\begin{array}{l}0.0015 \\
(0.0019)\end{array}$ \\
\hline$\Delta s_{t-1}$ & $\begin{array}{l}0.1406^{* * *} \\
(0.0337)\end{array}$ & $\begin{array}{l}0.0092 \\
(0.046)\end{array}$ & $\begin{array}{l}-0.016 \\
(0.014)\end{array}$ & $\begin{array}{l}-0.102 \\
(0.684)\end{array}$ & $\begin{array}{l}-0.0132 \\
(0.0246)\end{array}$ & $\begin{array}{l}0.6440 \\
(0.6724)\end{array}$ \\
\hline$\Delta s_{t-2}$ & $\begin{array}{l}-0.084^{* *} \\
(0.039)\end{array}$ & $\begin{array}{l}0.0596 \\
(0.0461)\end{array}$ & $\begin{array}{l}0.013 \\
(0.0126)\end{array}$ & $\begin{array}{l}-0.2418 \\
(0.543)\end{array}$ & & \\
\hline$\Delta \tilde{i}_{t-1}$ & $\begin{array}{l}-0.0083 \\
(0.0069)\end{array}$ & $\begin{array}{l}0.055^{* * *} \\
(0.0112)\end{array}$ & $\begin{array}{l}0.0001 \\
(0.0005)\end{array}$ & $\begin{array}{l}0.0289 \\
(0.5300)\end{array}$ & $\begin{array}{l}-0.0003 \\
(0.0003)\end{array}$ & $\begin{array}{l}-0.248^{* * *} \\
(0.0114)\end{array}$ \\
\hline$\Delta \tilde{i}_{t-2}$ & $\begin{array}{l}-0.0113^{*} \\
(0.0063)\end{array}$ & $\begin{array}{l}-0.0996^{* * *} \\
(0.011)\end{array}$ & $\begin{array}{l}-0.0002 \\
(0.0005)\end{array}$ & $\begin{array}{l}0.0218 \\
(0.2945)\end{array}$ & & \\
\hline$\theta$ & $\begin{array}{l}-0.0005 \\
(0.0003)\end{array}$ & $\begin{array}{l}-0.0004 \\
(0.0004)\end{array}$ & $\begin{array}{l}-0.0008^{* *} \\
(0.0004)\end{array}$ & $\begin{array}{l}-0.0334 \\
(0.0345)\end{array}$ & $\begin{array}{l}0.0002 \\
(0.0002)\end{array}$ & $\begin{array}{l}-0.076^{* * * *} \\
(0.005)\end{array}$ \\
\hline Regime 2 & & & & & & \\
\hline$\mu_{0}$ & $\begin{array}{l}-0.0004 \\
(0.0002)\end{array}$ & $\begin{array}{l}-0.197^{* * *} \\
(0.013)\end{array}$ & $\begin{array}{l}0.0006^{* *} \\
(0.0003)\end{array}$ & $\begin{array}{l}0.0011 \\
(0.004)\end{array}$ & $\begin{array}{l}0.0004^{* * *} \\
(0.0001)\end{array}$ & $\begin{array}{l}-0.051^{* * * *} \\
(0.010)\end{array}$ \\
\hline$\Delta s_{t-1}$ & $\begin{array}{l}-0.153^{* * *} \\
(0.0358)\end{array}$ & $\begin{array}{l}-23.106^{* * * *} \\
(1.655)\end{array}$ & $\begin{array}{l}0.173^{* * *} \\
(0.0339)\end{array}$ & $\begin{array}{l}0.255 \\
(0.7954)\end{array}$ & $\begin{array}{l}0.270^{* * *} \\
(0.034)\end{array}$ & $\begin{array}{l}-0.232 \\
(1.1838)\end{array}$ \\
\hline$\Delta s_{t-2}$ & $\begin{array}{l}0.0965^{* *} \\
(0.041)\end{array}$ & $\begin{array}{l}0.902 \\
(1.738)\end{array}$ & $\begin{array}{l}-0.0459 \\
(0.0418)\end{array}$ & $\begin{array}{l}0.288 \\
(0.738)\end{array}$ & & \\
\hline$\Delta \tilde{i}_{t-1}$ & $\begin{array}{l}0.0085 \\
(0.007)\end{array}$ & $\begin{array}{l}-1.143^{* * *} \\
(0.067)\end{array}$ & $\begin{array}{l}0.0015 \\
(0.001)\end{array}$ & $\begin{array}{l}-0.521 \\
(0.530)\end{array}$ & $\begin{array}{l}0.0009 \\
(0.0006)\end{array}$ & $\begin{array}{l}-0.2217^{* * *} \\
(0.0427)\end{array}$ \\
\hline$\Delta \tilde{i}_{t-2}$ & $\begin{array}{l}0.0117^{*} \\
(0.0069)\end{array}$ & $\begin{array}{l}1.072^{* * *} \\
(0.064)\end{array}$ & $\begin{array}{l}0.0012 \\
(0.0011)\end{array}$ & $\begin{array}{l}-0.2852 \\
(0.2948)\end{array}$ & & \\
\hline$\theta$ & $\begin{array}{l}0.0005 \\
(0.0003)\end{array}$ & $\begin{array}{l}0.227^{* * *} \\
(0.026)\end{array}$ & $\begin{array}{l}0.0029 \\
(0.0012)\end{array}$ & $\begin{array}{l}0.0338 \\
(0.0347)\end{array}$ & $\begin{array}{l}-0.0008^{* *} \\
(0.0004)\end{array}$ & $\begin{array}{l}-0.1576^{* * *} \\
(0.027)\end{array}$ \\
\hline
\end{tabular}

* significant at $10 \%$ level, $* *$ significant at $5 \%$ level, $* * *$ significant at $1 \%$ level. Standard errors in parentheses

\section{Conclusions}

This paper tests for the existence of a UIP-type relationship between the exchange rate and the interest differential by estimating first a benchmark linear Cointegrated VAR including the nominal exchange rate and the interest rate differential as well as central bank announcements, and then a Smooth Transition Cointegrated VAR (STCVAR) model incorporating nonlinearities and also taking into account the role 


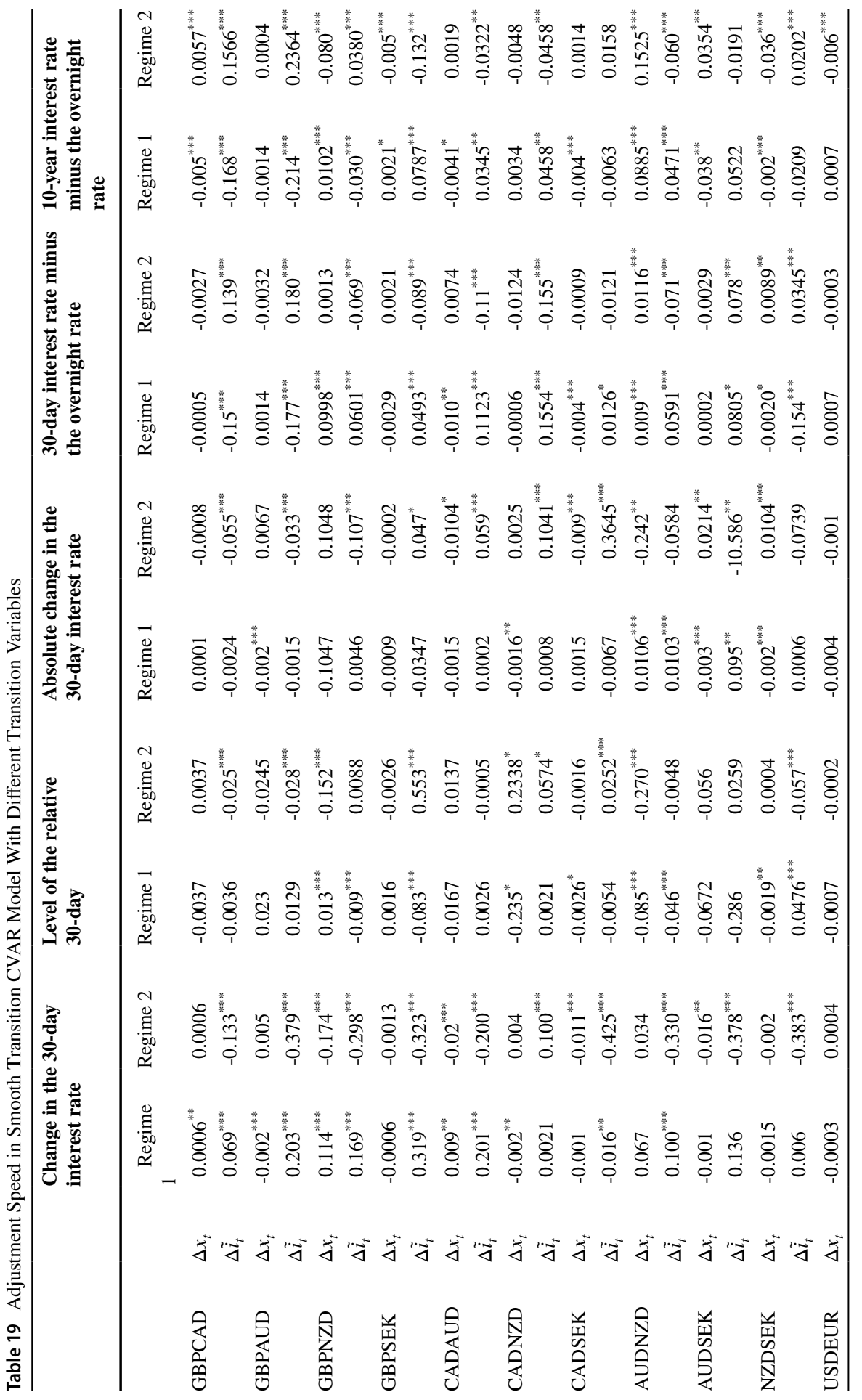




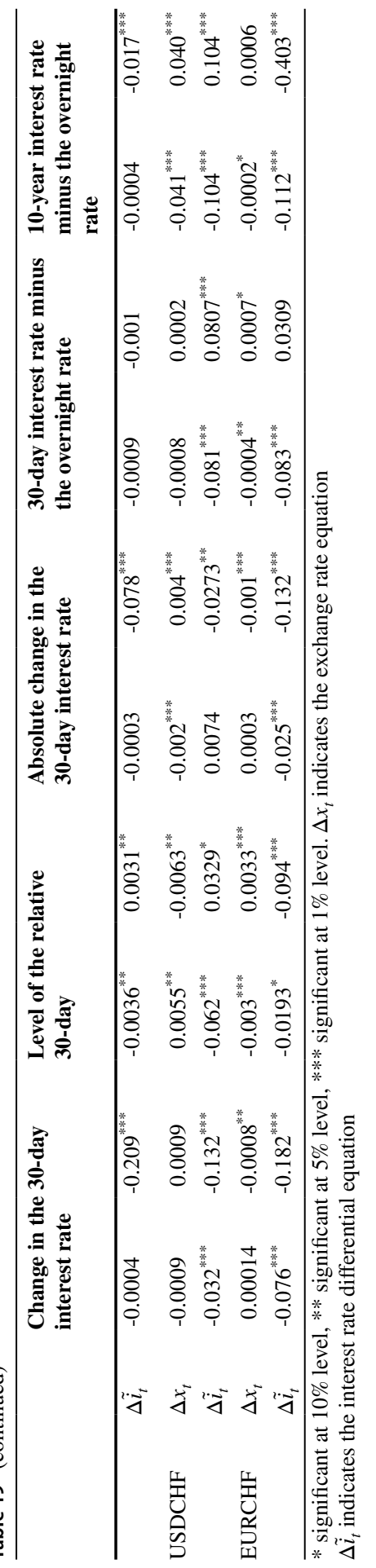


of interest rate expectations. The analysis is conducted for five inflation targeting countries (the UK, Canada, Australia, New Zealand and Sweden) and also, for comparison purposes, for three non-targeters (the US, the Euro-Area and Switzerland) using daily data from January 2000 to December 2020.

While we cannot find a UIP relationship in its strictest sense, we provide plenty of evidence of a long-run equilibrium relationship between the exchange rate and the interest rate differential. The main findings can be summarised as follows. First, the nonlinear framework appears to be more appropriate than the linear one to capture the adjustment towards the long-run equilibrium relationship between the exchange rate and the interest rate differential, which is consistent with the results of other related studies (see, for example, Sarno et al. 2005, 2006; Li et al. 2013). The estimated speed of adjustment is substantially faster in the nonlinear model, which lends greater support to the existence of a long run equilibrium than the linear one; similarly, the short-run dynamic linkages appear to be more significant in the nonlinear case. Second, interest rate expectations, a measure of central bank credibility which is often neglected in the context of investigating the long-run equilibrium relationship between the exchange rate and the interest rate differential, play an important role. In particular, a fast adjustment only occurs when the market expects the interest rate to increase in the near future, which suggests that central banks are perceived as more credible when sticking to their goal of keeping inflation at a low and stable rate. The change in the 30-day interest rate appears to be the most appropriate of the transition variables considered as indicated by the corresponding adjustment speeds. Third, central bank announcements have a more sizeable short- run effect in the nonlinear model which also includes interest rate expectations. Fourth, the long-run equilibrium holds better in inflation targeting countries, where the adjustment speed is faster than in non-targeting economies. This suggests that, in general, the inflation targeting framework tends to generate a higher degree of credibility for monetary authorities, thereby reducing deviations of the exchange rate from the long-run equilibrium.

\section{Appendix Transition Function Graphs}

Fig. 1 GBPCAD - Exchange Rate Equation

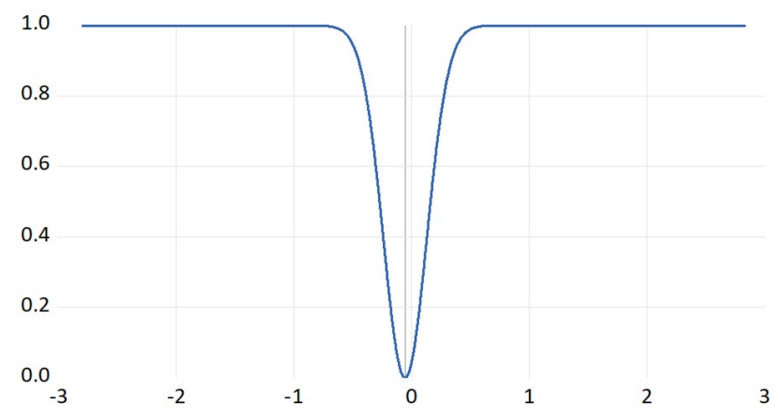


Fig. 2 GBPCAD - Interest Rate Equation

Fig. 3 GBPAUD - Exchange Rate Equation

Fig. 4 GBPAUD - Interest Rate Equation

Fig. 5 GBPNZD - Exchange Rate Equation
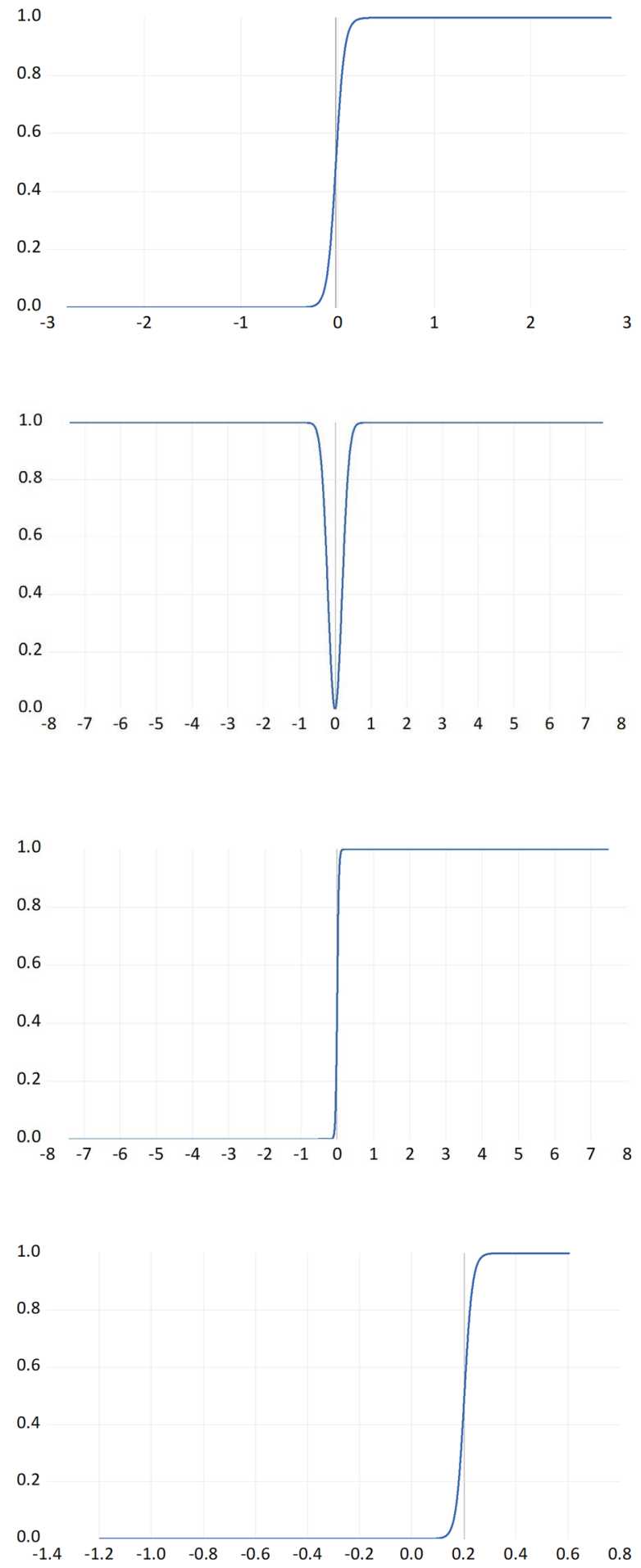
Fig. 6 GBPNZD - Interest Rate Equation

Fig. 7 GBPSEK - Exchange Rate Equation

Fig. 8 GBPSEK - Interest Rate Equation

Fig. 9 CADAUD - Exchange Rate Equation
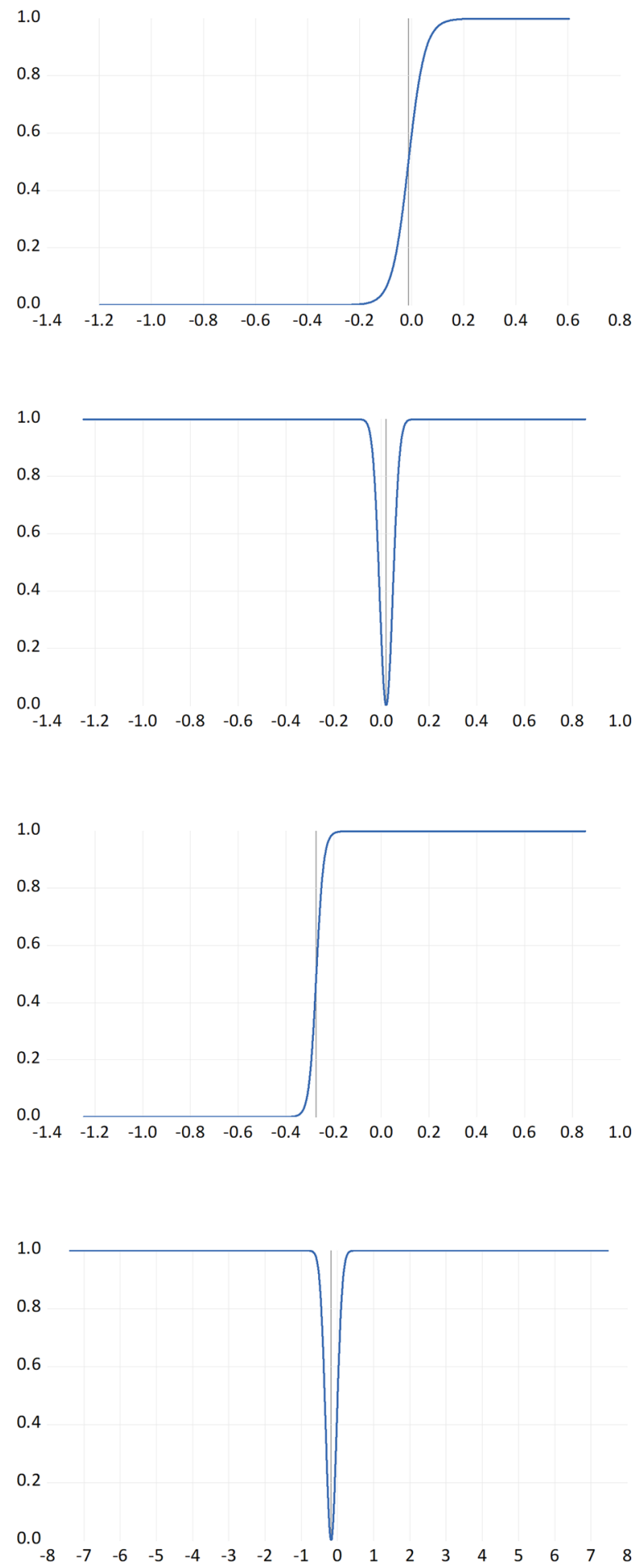
Fig. 10 CADAUD - Interest Rate Equation

Fig. 11 CADNZD - Exchange Rate Equation

Fig. 12 CADNZD - Interest Rate Equation

Fig. 13 CADSEK - Exchange Rate Equation
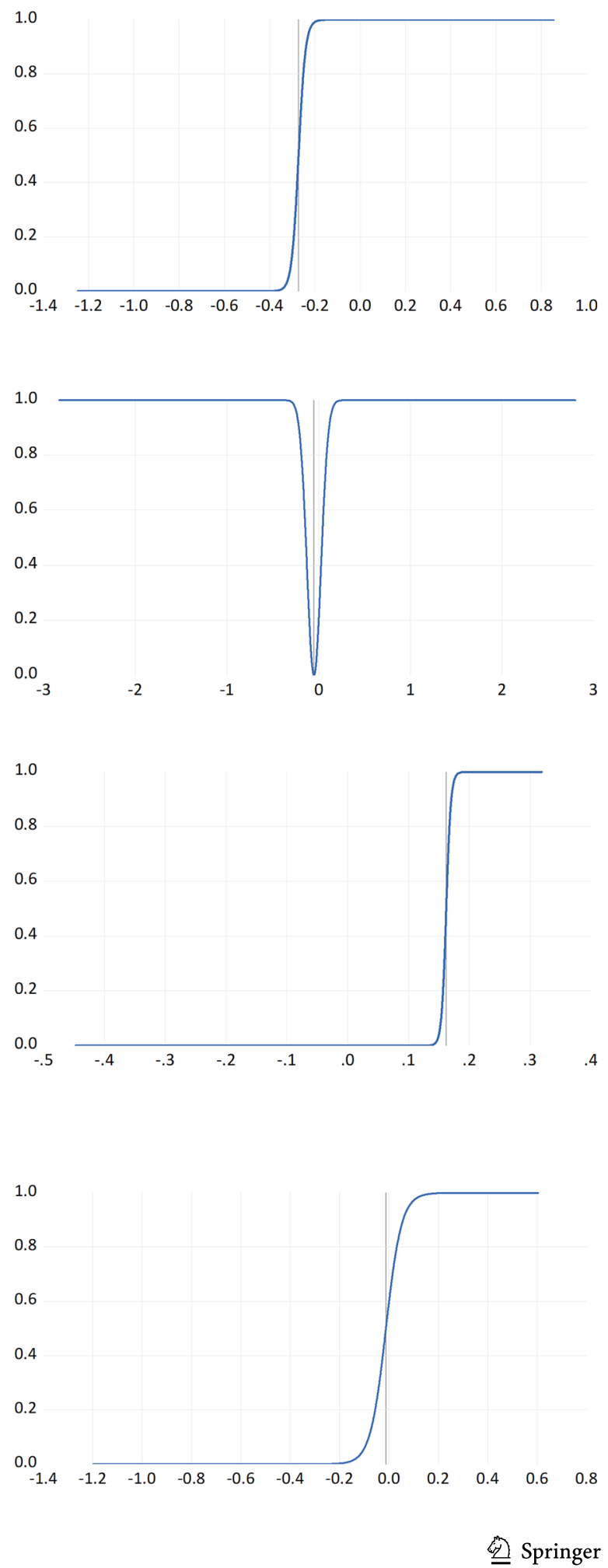
Fig. 14 CADSEK - Interest Rate Equation

Fig. 15 AUDNZD - Exchange Rate Equation

Fig. 16 AUDNZD - Interest Rate Equation

Fig. 17 AUDSEK - Exchange Rate Equation
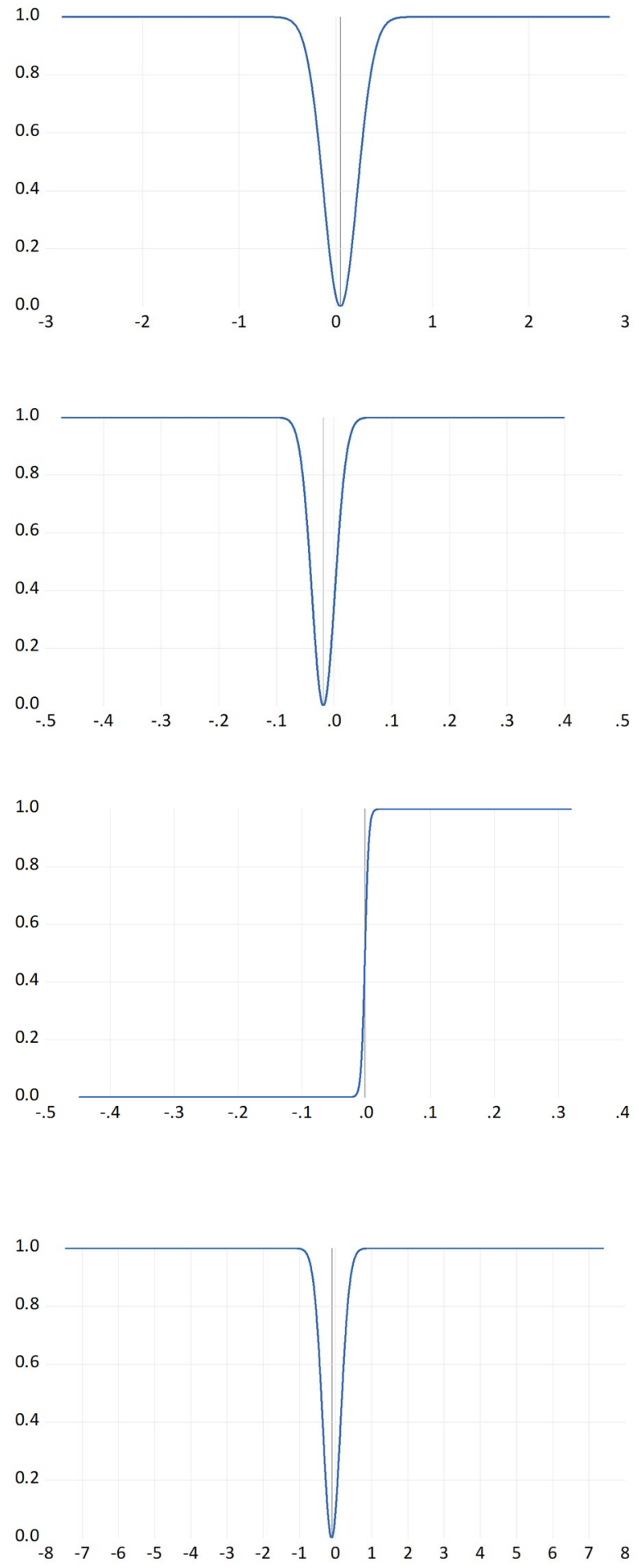

$\begin{array}{lllllllllllllllll}-8 & -7 & -6 & -5 & -4 & -3 & -2 & -1 & 0 & 1 & 2 & 3 & 4 & 5 & 6 & 7 & 8\end{array}$ 
Fig. 18 AUDSEK - Interest Rate Equation

Fig. 19 NZDSEK - Exchange Rate Equation

Fig. 20 NZDSEK - Interest Rate Equation

Fig. 21 USDEUR - Exchange Rate Equation
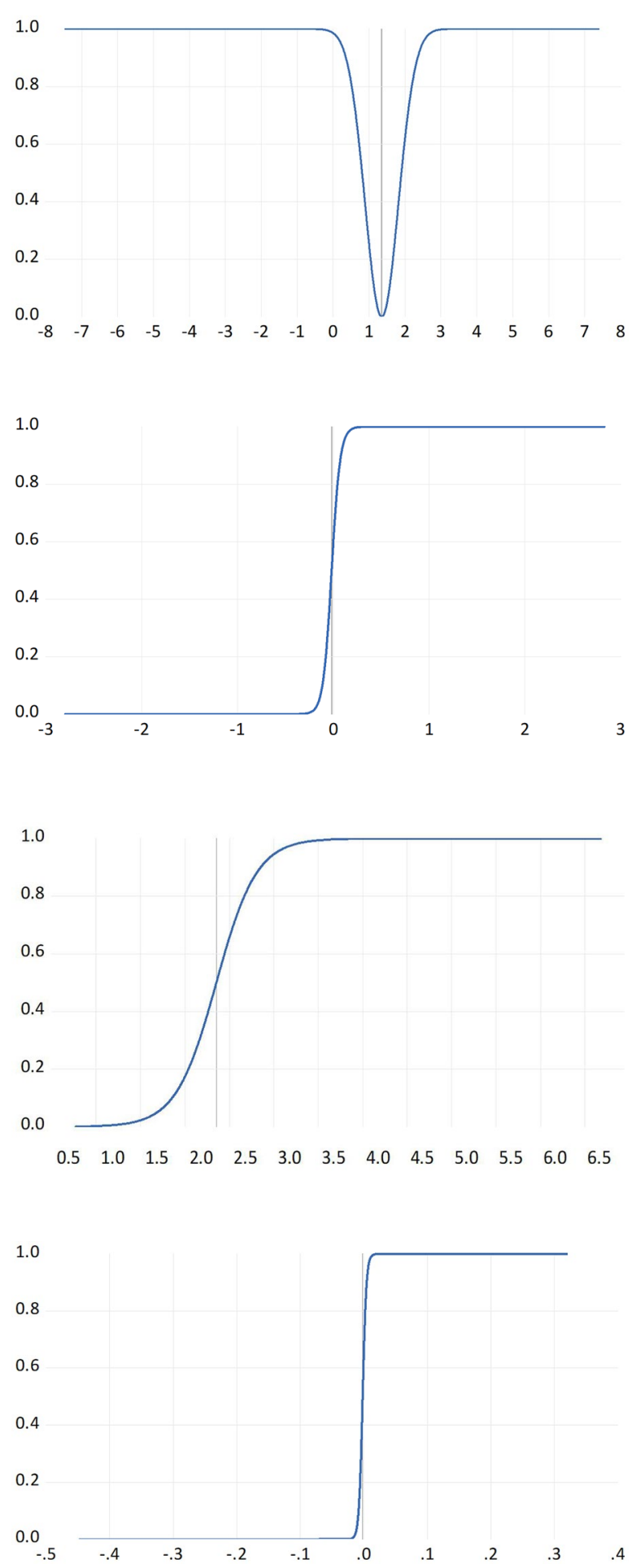
Fig. 22 USDEUR - Interest Rate Equation

Fig. 23 USDCHF - Exchange Rate Equation

Fig. 24 USDCHF - Interest Rate Equation

Fig. 25 EURCHF - Exchange Rate Equation

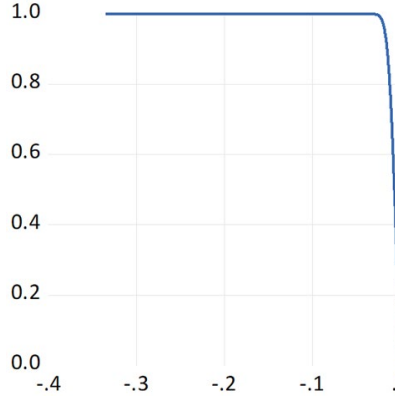

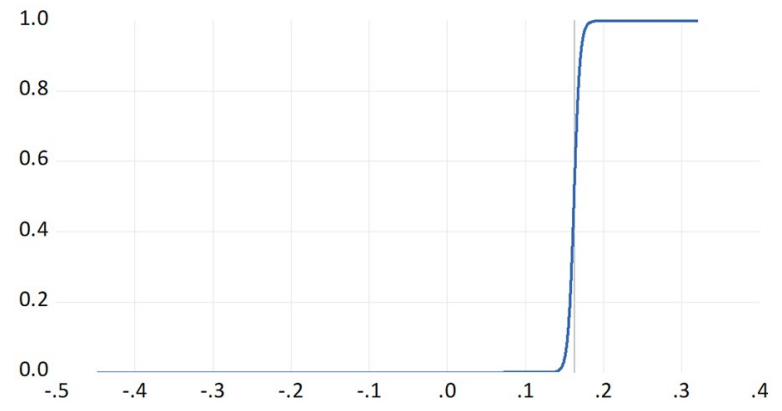
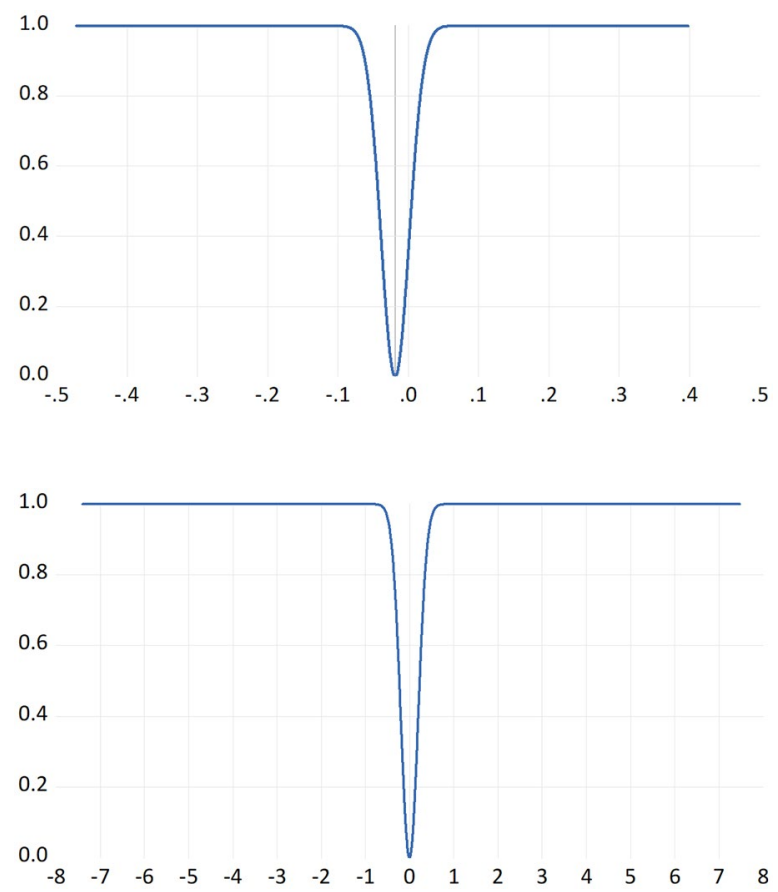
Fig. 26 EURCHF - Interest Rate Equation

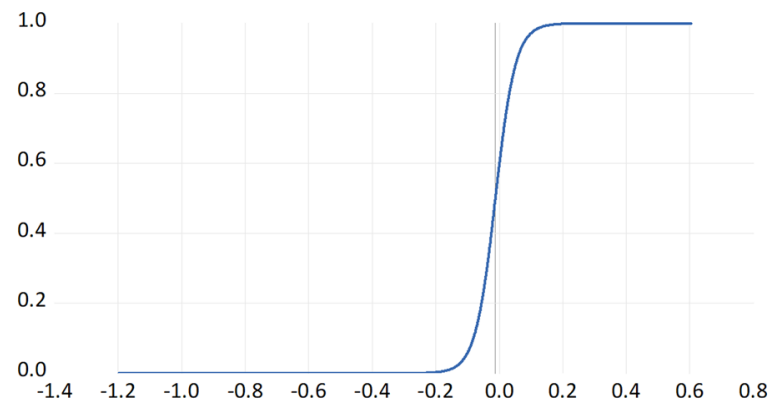

Open Access This article is licensed under a Creative Commons Attribution 4.0 International License, which permits use, sharing, adaptation, distribution and reproduction in any medium or format, as long as you give appropriate credit to the original author(s) and the source, provide a link to the Creative Commons licence, and indicate if changes were made. The images or other third party material in this article are included in the article's Creative Commons licence, unless indicated otherwise in a credit line to the material. If material is not included in the article's Creative Commons licence and your intended use is not permitted by statutory regulation or exceeds the permitted use, you will need to obtain permission directly from the copyright holder. To view a copy of this licence, visit http://creativecommons.org/ licenses/by/4.0/.

\section{References}

Amri S (2008) Analysing the forward premium anomaly using a Logistic Smooth Transition Regression model. Econom Bullet 6(26):1-18

Baillie RT, Chang SS (2011) Carry trades, momentum trading and the forward premium anomaly. Journal of Financial Markets 14(3):441-464

Baillie RT, Kilic R (2006) Asymmetry and nonlinearity in uncovered interest rate parity. J Int Money Financ 25(2):22-47

Banerjee A, Singh MM (2006) Testing real interest parity in emerging markets (No. 6-249). International Monetary Fund

Brenner RJ, Kroner KF (1995) Arbitrage, cointegration, and testing the unbiasedness hypothesis in financial markets. J Fin Quant Anal 23-42

Canterbery ER (2000) Rational bubbles and uncovered interest-rate parity: retrospective and prospective. Editorial Policy 1(2000):167-178

Chen CR, Ainina F (1994) Financial ratio adjustment dynamics and interest rate expectations. J Bus Financ Acc 21(8):1111-1126

Chinn MD, Quayyum S (2012) Long horizon uncovered interest parity re-assessed (No. w18482). National Bureau of Economic Research

Clarida RH, Sarno L, Taylor MP, Valente G (2003) The out-of-sample success of term structure models as exchange rate predictors: a step beyond. J Int Econ 60(1):61-83

Clarida RH, Taylor MP (1997) The term structure of forward exchange premiums and the forecastability of spot exchange rates: correcting the errors. Rev Econ Stat 79(3):353-361

Connolly E, Kohler M (2004) News and Interest Rate Expectations: A Study of Six Central Banks. Reserve Bank of Australia Conference - 2004

Cook T, Hahn TK (1990) Interest rate expectations and the slope of the money market yield curve. FRB Richmond Economic Review 76(5):3-26

Coulibaly D, Kempf H (2019) Inflation targeting and the forward bias puzzle in emerging countries. J Int Money Financ 90:19-33

Eitrheim Ø, Teräsvirta T (1996) Testing the adequacy of smooth transition autoregressive models. J Econom 74(1):59-75 
Engel C (1996) The forward discount anomaly and the risk premium: A survey of recent evidence. J Empir Financ 3(2):123-192

Escribano A, Jordá O (2001) Testing nonlinearity: Decision rules for selecting between logistic and exponential STAR models. SpanEconRev 3(3):193-209

Froot KA, Thaler RH (1990) Anomalies: foreign exchange. J Econ Perspect 4(3):179-192

Georgoutsos DA, Kouretas GP (2002) Cointegration, uncovered interest parity and the term structure of interest rates: some International evidence

Gregory AW (1987) Testing interest rate parity and rational expectations for Canada and the United States. Can J Econ 289-305

Jiang C, Li XL, Chang HL, Su CW (2013) Uncovered interest parity and risk premium convergence in Central and Eastern European countries. Econ Model 33:204-208

Johansen S (1991) Estimation and hypothesis testing of cointegration vectors in Gaussian vector autoregressive models. Econometrica: J Econom Soc 1551-1580

Johansen S, Juselius K (1992) Testing structural hypothesis in a multivariate cointegration analysis of the PPP and the UIP for UK. J Econom 53:211-244

Juselius K (2017) Using a theory-consistent CVAR scenario to test an exchange rate model based on imperfect knowledge. Econometrics 5(3):30

Juselius K (2018) The cointegrated VAR methodology. In Oxford Research Encyclopedia of Economics and Finance

Juselius K, Stillwagon JR (2018) Are outcomes driving expectations or the other way around? An I (2) CVAR analysis of interest rate expectations in the dollar/pound market. J Int Money Financ 83:93-105

Lacerda M, Fedderke JW, Haines LM (2010) Testing for purchasing power parity and uncovered interest parity in the presence of monetary and exchange rate regime shifts. South African J Econ 78(4):363-382

Li D, Ghoshray A, Morley B (2012) Measuring the risk premium in uncovered interest parity using the component GARCH-M model. Int Rev Econ Financ 24:167-176

Li D, Ghoshray A, Morley B (2013) An empirical study of nonlinear adjustment in the UIP model using a smooth transition regression model. Int Rev Financ Anal 30:109-120

Lothian JR (2016) Uncovered interest parity: The long and the short of it. J Empir Financ 36:1-7

Lothian JR, Wu L (2011) Uncovered interest-rate parity over the past two centuries. J Int Money Financ 30(3):448-473

Lukkonen RSP, Teräsvirta T (1988) Testing Linearity Against Smooth Transition Autoregressive Models. Biometrica 75(3):491-499

Lyons RK (2001) The microstructure approach to exchange rates, vol 333. MIT press, Cambridge, MA

Mauleón I (1998) Interest rate expectations and the exchange rate. Int Adv Econ Res 4(2):179-191

Moniz A, de Jong F (2014) Predicting the impact of central bank communications on financial market investors' interest rate expectations. In European Semantic Web Conference (pp. 144-155). Springer, Cham

Moore MJ, Roche MJ (2010) Solving exchange rate puzzles with neither sticky prices nor trade costs. J Int Money Financ 29(6):1151-1170

Neumann MJ, Von Hagen J (2002) Does inflation targeting matter? (No. B 01-2002). ZEI working paper

Obstfeld M (1987) Peso problems, bubbles, and risk in the empirical assessment of exchange-rate behavior (No. w2203). National Bureau of Economic Research

Rao CR (1948) Tests of significance in multivariate analysis. Biometrika 35(1/2):58-79

Ripatti A (2001) Vector autoregressive processes with nonlinear time trends in cointegrating relations. Macroecon Dyn 5(4):577-597

Rosa C, Verga G (2018) The impact of central bank announcements on asset prices in real time. Thirteenth issue (June 2008) of the International Journal of Central Banking

Sager MJ, Taylor MP (2004) The impact of European Central Bank Governing Council announcements on the foreign exchange market: a microstructural analysis. J Int Money Financ 23(7-8):1043-1051

Salisu AA, Vo XV (2020) Predicting stock returns in the presence of COVID-19 pandemic: The role of health news. Int Rev Financ Anal 71. https://doi.org/10.1016/j.irfa.2020.101546

Sarno L (2005) Towards a solution to the puzzles in exchange rate economics: Where do we stand? Canadian Journal of Economics/revue Canadienne D'économique 38(3):673-708

Sarno L, Valente G, Leon H (2005) The forward bias puzzle and nonlinearity in deviations from uncovered interest parity, a new perspective. University Of Warwick, Mimeo 
Sarno L, Valente G, Leon H (2006) Nonlinearity in deviations from uncovered interest parity: an explanation of the forward bias puzzle. Rev Fin 10(3):443-482

Teräsvirta T, Yang Y (2014) Linearity and misspecification tests for vector smooth transition regression models. Creates Research Papers 2014-04, Department of Economics and Business Economics, Aarhus University

Tietz R (2019) How does the Fed manage interest rate expectations?. Available at SSRN 3254094

Weber E (2006) British interest rate convergence between the US and Europe: A recursive cointegration analysis (No. 2006, 005). SFB 649 Discussion Paper

Zivot E (2000) Cointegration and forward and spot exchange rate regressions. J Int Money Financ 19(6):785-812

Publisher's Note Springer Nature remains neutral with regard to jurisdictional claims in published maps and institutional affiliations. 